\title{
A putative exchange factor for Rho1 GTPase is required for initiation of cytokinesis in Drosophila
}

\author{
Sergei N. Prokopenko, ${ }^{1}$ Anthony Brumby, ${ }^{4}$ Louise $\mathrm{O}^{\prime}$ Keefe,${ }^{4}$ Leanne Prior, ${ }^{4}$ Yuchun He, ${ }^{2}$ \\ Robert Saint, ${ }^{4}$ and Hugo J. Bellen ${ }^{1,2,3,5}$

\begin{abstract}
${ }^{1}$ Program in Developmental Biology, ${ }^{2}$ Howard Hughes Medical Institute, and ${ }^{3}$ Department of Molecular and Human Genetics, Baylor College of Medicine, Houston, Texas 77030 USA; ${ }^{4}$ Department of Genetics, University of Adelaide,
\end{abstract} \\ Adelaide SA 5005, Australia
}

Cytokinesis ensures the successful completion of the cell cycle and distribution of chromosomes, organelles, and cytoplasm between daughter cells. It is accomplished by formation and constriction of an actomyosin contractile ring that drives the progression of a cleavage furrow. Microinjection experiments and in vitro transfection assays have suggested a requirement for small GTPases of the Rho family in cytokinesis. Yet, the identity of proteins regulating Rho signaling pathways during cytokinesis remains unknown. Here we show that in Drosophila, Pebble (Pbl), a putative exchange factor for Rho GTPases (RhoGEF), is required for the formation of the contractile ring and initiation of cytokinesis. The dynamics of $\mathrm{Pbl}$ expression and its distribution during mitosis, as well as structure-function analysis, indicate that it is a key regulatory component of the pathway. pbl interacts genetically with Rho1, but not with Rac1 or Cdc42, and Pbl and Rho1 proteins interact in vivo in yeast. Similar to mutations in $p b l$, loss of Rho1 or expression of a dominant-negative Rho1 blocks cytokinesis. Our results identify Pbl as a RhoGEF specifically required for cytokinesis and linked through Rho1 activity to the reorganization of the actin cytoskeleton at the cleavage furrow.

[Key Words: Cytokinesis; contractile ring; RhoGEF; Rhol GTPase; pebble]

Received June 2, 1999; revised version accepted July 7, 1999.

Cytokinesis in animal cells is accomplished by formation and constriction of a cleavage furrow that divides a cell in two daughter cells. The driving force behind this constriction is an actomyosin contractile ring that forms at the cell equator in late anaphase. The assembly of the contractile ring involves local reorganization of actin filaments around the cell equator into a cortical complex consisting, in addition to actin, of myosin, septins, and other cytoskeletal proteins (Goldberg et al. 1998). In Drosophila, genetic analysis and biochemical studies have led to the identification of a number of genes required for the assembly or function of the contractile ring (Field et al. 1999). Structural components of the contractile ring include actin, the regulatory light chain of nonmuscle myosin [encoded by spaghetti-squash (sqh), Karess et al. 1991], septins [Peanut (Pnut) (Neufeld and Rubin 1994), Septin-1 (Fares et al. 1995), and Septin-2 (Field et al. 1996)], and actin-binding proteins cofilin [encoded by twinstar (tsr), Gunsalus et al. 1995], profilin [encoded by chickadee (chic), Giansanti et al. 1998), and anillin (Field and Alberts 1995; Giansanti et al. 1999)]. Mutations in

${ }^{5}$ Corresponding author.

E-MAIL hbellen@bcm.tmc.edu; FAX (713) 798-8515. $s q h, p n u t, t s r$, and chic result in a failure of cytokinesis, most likely due to defects in contractile ring organization or function. Yet, little is known about the roles of these proteins in contractile ring assembly, stabilization, constriction, and disassembly or about the molecular machinery regulating actin cytoskeleton reorganization during cytokinesis.

Small guanosine triphosphatases (GTPases) of the Rho family control organization of the cytoskeletal architecture in all eukaryotic cells and have been implicated in many actin-based processes including cell motility, cell adhesion, chemotaxis, axon guidance, and cytokinesis (for review, see Van Aelst and D'Souza-Schorey 1997; Hall 1998). Rho GTPases act as molecular switches, cycling between inactive (GDP-bound) and active (GTPbound) states. Rho proteins are activated by guanine nucleotide exchange factors (GEFs), which enhance the exchange of bound GDP for GTP, and are inactivated by GTPase-activating proteins (GAPs), which increase the intrinsic GTPase activity of Rho proteins. Activation of Rho GTPases results in a conformational change of the protein revealing structural domains required for the interaction with downstream target proteins. Thus, the intracellular ratio of the GTP/GDP-bound forms of Rho 
proteins determines the activation of signal transduction pathways regulating the spatial and temporal reorganization of cytoskeletal architecture.

Here, we show that in Drosophila, a putative guanine nucleotide exchange factor (Pbl) and its downstream effector (Rhol GTPase) are required for the initiation of cytokinesis. We propose a molecular pathway that links a RhoGEF through the activity of small GTPase to reorganization of the actin cytoskeleton at the cell equator leading to the assembly of a contractile ring and initiation of cytokinesis. We provide several lines of evidence suggesting that $\mathrm{Pbl}$ is a key regulatory component of this pathway acting upstream of Rhol to regulate the behavior of cytoskeletal and structural proteins known to be required for cytokinesis.

\section{Results}

Mutations in pbl result in the absence of a contractile ring and block of cytokinesis

We and others have demonstrated previously that mutations in $\mathrm{pbl}$ lead to a complete block of cytokinesis in mitotic cycle 14 (Hime and Saint 1992; Lehner 1992). Later rounds of nuclear divisions without cytokinesis result in the formation of polyploid multinucleate cells (Fig. 1A,B). Other events of the cell cycle (including nuclear envelope breakdown, chromosome condensation, and assembly and function of mitotic spindle) are not affected (Hime and Saint 1992; Lehner 1992), and during cycle 15 two mitotic figures are formed that independently enter anaphase (Fig. 1C,D). Affected cells fail to initiate a cleavage furrow (Fig. 1D), suggesting a defect in contractile ring function. To further characterize the defects in cytokinesis, we examined the localization of actin, Pnut, and anillin, components of the contractile ring, in $\mathrm{pbl}$ mutant cells. In wild-type cells, actin is associated with the cell cortex throughout mitosis and accumulates in the equatorial region of the cell, in which the contractile ring is assembled (Fig. 1E). Anillin, an actin-binding protein required for cytokinesis, is thought to play a role in organizing contractile domains of the actin cytoskeleton (Field and Alberts 1995; Giansanti et al. 1999). In wild-type cells, anillin accumulates at the cleavage furrow at the onset of anaphase and is restricted to the contractile ring during anaphase and telophase (Fig. 1H). Pnut, a member of the septin family of proteins (Neufeld and Rubin 1994), accumulates at the cleavage furrow in late anaphase and is associated with the contractile ring during telophase (Fig. 1J). During cycle 14 in pbl mutant cells, actin (Fig. 1F), anillin (Fig. 1I), and Pnut (Fig. 1K) fail to relocalize from the cell cortex to the cleavage furrow. Subsequently, the cleavage furrow is not initiated (arrows in Fig. $1 \mathrm{~F}, \mathrm{I}, \mathrm{K}$ ) and cytokinesis fails. Similarly, in later rounds of cell division, actin, anillin, and Pnut fail to accumulate at the equatorial region of the cell, and there are no signs of a cleavage furrow (Fig. $1 G$; data not shown). These results indicate that in $p b 1$ mutant cells the contractile ring does not assemble, leading to a failure of cytokinesis.

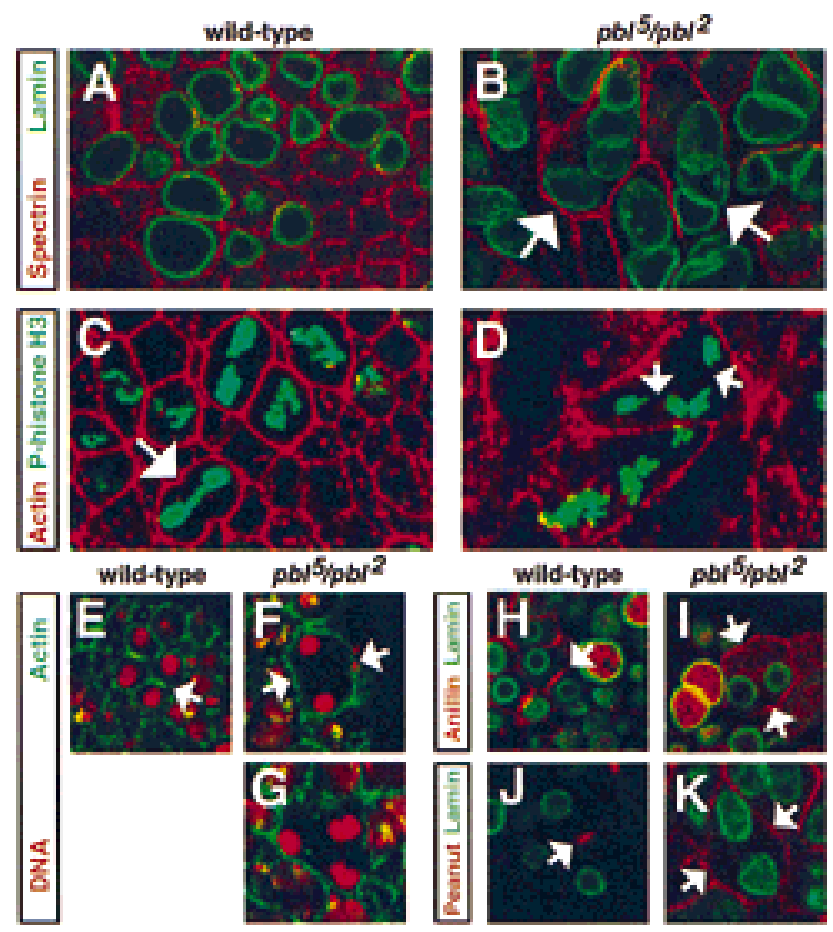

Figure 1. Absence of a contractile ring and failure of cytokinesis in $p b l$ mutants. Wild-type $(A)$ and $p b 1^{5} / p b 1^{2}(B)$ embryos stained with anti- $\alpha$-spectrin (red) to reveal plasma membrane and anti-lamin (green) to mark nuclei. Ectodermal cells of a wild-type embryo $(A)$ contain only one nuclear lamina (nucleus) per cell, whereas several nuclei can be found in pbl mutant cells (B). Absence of cytokinesis in cell divisions following mitotic cycle 14 results in accumulation of multiple nuclei per cell (arrows). Wild-type $(C)$ and $p b l^{5} / \mathrm{pbl}^{2}(D)$ embryos stained with anti-actin (red) to mark plasma membrane and anti-phosphohistone H3 (green) to mark chromosomes during mitosis. Wildtype cells $(C)$ form a single mitotic apparatus per cell and initiate contraction of the cleavage furrow (arrow) in late anaphase. In polyploid $p b l$ mutant cells $(D)$, there are no signs of cleavage, and during mitotic cycle 15, two mitotic apparatuses are formed (arrows) that independently enter anaphase. Wild-type $(E, H, J)$ and $p b 1^{5} / p b 1^{2}(F, G, I, K)$ embryos stained with anti-actin $(E-G$, green), anti-anillin $(H, I$, red), and anti-Pnut $(J, K$, red) as markers of a contractile ring. Embryos in $E-G$ were counterstained with propidium iodide (red) to mark DNA, and embryos in $H-K$ were counterstained with anti-lamin (green) to reveal nuclei. In dividing wild-type cells, actin $(E)$, anillin $(H)$, and Pnut $(J)$ accumulate at the equatorial region in which the contractile ring is assembled during late anaphase. They remain enriched at the equator through telophase (arrows in $E, H, J)$. During cycle 14 in pbl mutant cells, actin $(F)$, anillin $(I)$, and Pnut $(K)$ do not accumulate at the equatorial region and remain associated with plasma membrane. Similarly, during later mitotic cycles $(G)$ there are no signs of contractile ring formation.

\section{pbl encodes a novel RhoGEF related to the mouse Ect2 oncoprotein}

To clone $p b l$, we used recently identified P-element alleles of pbl (Salzberg et al. 1997). Genomic fragments flanking the sites of P-element insertions were isolated and used to screen an embryonic cDNA library. Database searches revealed that $p b l$ encodes a novel guanine 
nucleotide exchange factor for small $G$ proteins of the Rho family (RhoGEF) related to the mouse Ect2 oncoprotein (Miki et al. 1993; Fig. 2A,B). Common functional domains of $\mathrm{Pbl}$ and Ect2 include the $\mathrm{Dbl}$ homology (DH) and pleckstrin homology $(\mathrm{PH})$ domains (in $\mathrm{Pbl}$, amino acids 390-574 and 600-718, respectively) that are found in tandem in all RhoGEFs (Whitehead et al. 1997). Mammalian members of the RhoGEF family are considered to be potential oncogenes as their truncated forms often induce transformed foci when overexpressed in cultured fibroblasts. The DH domain catalyzes GDP/GTP exchange through direct binding to its effector GTPase (Hart et al. 1994; Zheng et al. 1995; Liu et al. 1998). The PH domain (Shaw 1996), always carboxy-terminal to the $\mathrm{DH}$ domain in RhoGEFs, is thought to be required for membrane or cytoskeletal targeting of the protein and in enhancement of the catalytic activity of the adjacent DH domain (Whitehead et al. 1995; Zheng et al. 1996; Liu et al. 1998; Sterpetti et al. 1999). At the amino terminus, $\mathrm{Pbl}$ and Ect2 share two BRCT (BRCA1 carboxyl terminus) domains (in Pbl, amino acids 113-198 and 208-291) initially identified in the familial breast and ovarian cancer susceptibility gene BRCA1 (Bork et al. 1997; Callebaut and Mornon 1997). BRCT domains are found in proteins involved in DNA metabolism and cell cycle checkpoint control and are thought to be protein-protein interaction modules. In addition, $\mathrm{Pbl}$ contains a putative nuclear localization signal (NLS) (amino acids 306-322) and a PEST sequence (amino acids 371-383) (Fig. 2B), which often serves as a proteolytic signal to target proteins for rapid degradation.

Several lines of evidence suggest that the $p b 1$ cDNA we cloned corresponds to the $p b l$ gene. First, four independently generated P-element alleles that fail to complement other $\mathrm{pbl}$ alleles are inserted in the $5^{\prime}$-untranslated region (UTR) or open reading frame (ORF) of pbl. Second, each $\mathrm{P}$ element is revertible to wild type (Salzberg et al. 1997; this study). Third, the molecular lesions associated with three EMS-induced $\mathrm{pbl}$ mutations were identified (Fig. 2A,B). Mutations in $p b l^{2}$ and $\mathrm{pbl}^{3}$ cause premature termination at Q37 (CAG to TAG) and W185 (TGG to TAG), respectively, whereas a V531D
A

PBL
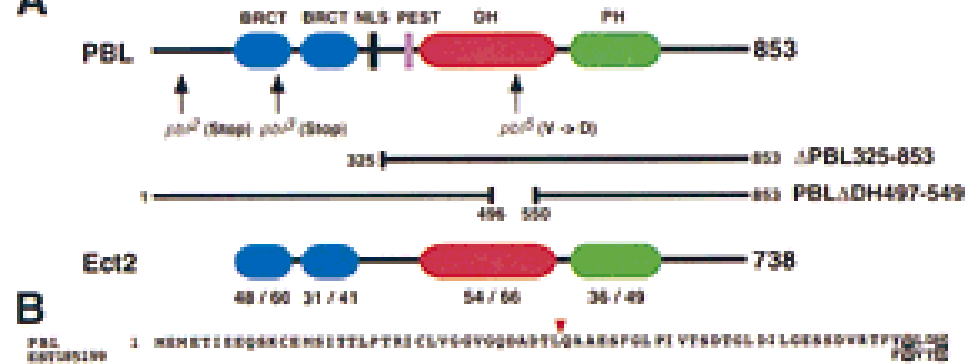

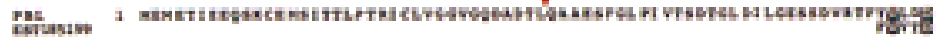

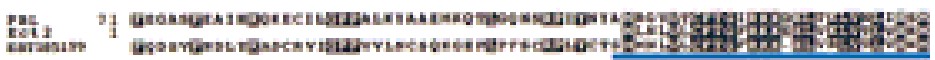
盟,

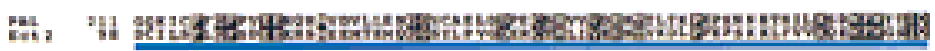

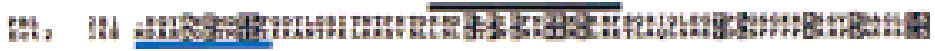

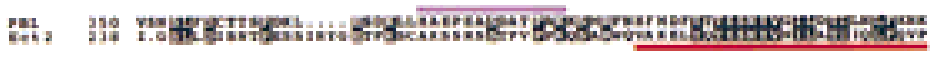

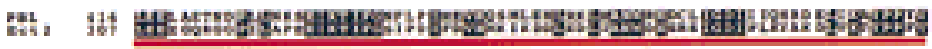

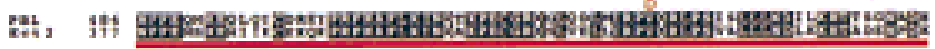

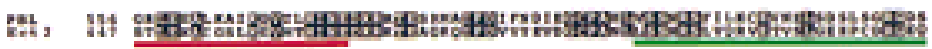

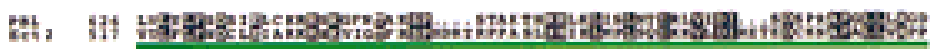

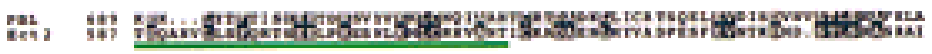

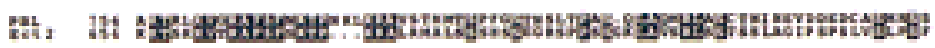

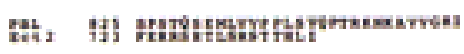

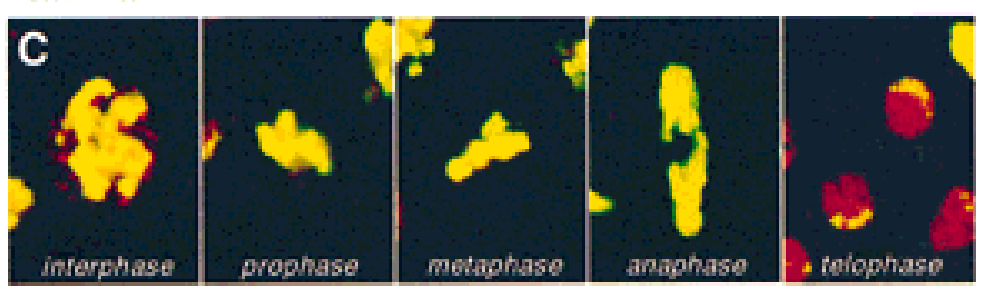

Figure 2. $p b 1$ encodes an exchange factor for small G proteins of the Rho family. (A) Domain structure of $\mathrm{Pbl}$ and Ect2. The two proteins are represented schematically with functional domains shown in color. The lengths of $\mathrm{Pbl}$ and Ect2 are 853 and 738 amino acids, respectively. Overall, the two proteins are $40 \%$ identical and $61 \%$ similar. Percent identity/similarity between respective domains is shown below the Ect2 protein. Location of mutations and amino acid changes in $p b l$ alleles are indicated by arrows. Lines below the Pbl protein represent constructs used to generate new alleles of pbl in transgenic flies. (BRCT) BRCA1 carboxyl terminus; (DH) Dbl homology; (NLS) nuclear localization signal; $(\mathrm{PH})$ pleckstrin homology. (B) Alignment of amino acid sequences of $\mathrm{Pbl}$, mouse Ect2, and predicted ORF from human EST185199. Black boxes indicate identical amino acids. Common functional domains of $\mathrm{Pbl}$ and Ect2 are underlined. The NLS and PEST sequences of $\mathrm{Pbl}$ are marked above its sequence. All domains are indicated with the same colors as in A. Amino acids 66157 of $\mathrm{Pbl}$ show $42 \%$ identity (56\% similarity) to a predicted amino acid sequence of EST185199 (nucleotides 39-314) from human colon carcinoma cell line. In addition, amino acids $44-185$ of $\mathrm{Pbl}$ show $27 \%$ identity $149 \%$ similarity) to a predicted amino acid sequence of human EST zs58b08.r1 (nucleotides 248-661; data not shown). Positions of protein truncation caused by nonsense mutations in the $p b l^{2}$ and $p b l^{3}$ alleles $(\mathrm{Q} 37$ Ter and W185Ter, respectively) are marked with red triangles. The red letter $\mathrm{D}$ denotes the V531D mutation within the DH domain in the $p b 1^{5}$ allele. The GenBank accession nos. are L11316 (ect2), AA313301 (EST185199), and AA287172 (EST zs58b08.r1). The BRCT domains and $\mathrm{DH}$ and $\mathrm{PH}$ domains of Ect 2 were defined according to Callebaut and Mornon (1997) and Schultz et al. (1998), respectively. $(C)$ Mitotic figures in cycle 14 domains of a wild-type embryo stained with anti-Pbl (red) and antiphosphohistone H3 (yellow) to mark chromosomes during mitosis. $\mathrm{Pbl}$ protein is not detected during late prophase, metaphase, and anaphase. $\mathrm{Pbl}$ has the highest levels of expression in telophase and interphase nuclei. 
(GTT to GAT) mutation in $p b 1^{5}$ affects a conserved valine within the most highly conserved region (CR3) of the $\mathrm{DH}$ domain. A mutation in this residue has been shown to dramatically reduce the nucleotide exchange activity of other RhoGEFs (Liu et al. 1998). We conclude that $\mathrm{Pbl}$ is a putative RhoGEF related to the mouse Ect2 protein.

\section{Pbl redistribution during mitosis parallels the onset of cytokinesis}

To investigate the subcellular distribution of the protein during the cell cycle, we raised anti-Pbl polyclonal antibodies. Double stainings of wild-type embryos undergoing mitotic cycle 14 with the anti-phospho-histone H3 antibody, which marks chromosomes during mitosis (Hendzel et al. 1997), revealed that $\mathrm{Pbl}$ is expressed dynamically during the cell cycle (Fig. 2C). We observed no $\mathrm{Pbl}$ protein during late prophase, metaphase, and early anaphase. $\mathrm{Pbl}$ protein is first detected in late anaphase, when it colocalizes with separating daughter chromosomes. The highest levels of $\mathrm{Pbl}$ staining were found in telophase nuclei, and this staining persisted during interphase of the following mitotic cycle. As we never ob- served $\mathrm{Pbl}$ at the onset of mitosis, it appears that it is rapidly degraded during each cycle of cell division, presumably after being released from the nucleus upon disassembly of the nuclear envelope in prophase. Further analyses with antibodies against lamin to mark nuclei and $\alpha$-spectrin to stain plasma membranes demonstrated that in late anaphase, there are low levels of $\mathrm{Pbl}$ protein at the plasma membrane and in the cytoplasm (Fig. 3AC). Initiation of cytokinesis, as judged by the appearance of the cleavage furrow (arrowheads in Fig. 3B) and reassembly of nuclear laminae (Fig. 3A), coincides with the accumulation of $\mathrm{Pbl}$ at the cleavage furrow. As the cleavage furrow progresses (arrowheads in Fig. 3E), Pbl accumulates at the equator between dividing cells (Fig. $3 \mathrm{cf}$. arrows in D,F,G with A) and in the nuclei of the daughter cells (Fig. 3G). Pbl translocation to the equatorial region beneath the cleavage furrow (Fig. $3 \mathrm{H}$ ) parallels the accumulation of anillin (Fig. 3I) and Pnut (Fig. 3J) at the equator in which the contractile ring is assembled. In telophase and early interphase cells, the protein is strongly enriched in the nuclei (Fig. $3 \mathrm{~K}$ ) and is found at low levels at the cortex (data not shown). Hence, during mitosis subcellular distribution of $\mathrm{Pbl}$ undergoes dynamic changes and $\mathrm{Pbl}$ is associated with the cleavage furrow
Figure 3. $\mathrm{Pbl}$ is localized to the cell cortex and cleavage furrow during cytokinesis. $(A-G)$ Wild-type embryos stained with anti-Pbl $(A, D, G$, red), anti-la$\min (A, D, G$, green) to mark nuclei, anti- $\alpha$-spectrin $(B, E, G$, blue) to mark plasma membrane, and merged images $(C, F)$. Upon initiation of cytokinesis, $\mathrm{Pbl}$ is cortical and cytoplasmic $(A-C$, the cell is outlined with a dotted line). As the cleavage furrow progresses (arrowheads in $B, E$ ), $\mathrm{Pbl}$ accumulates as two spots at the equator (arrows in $D, F, G$ ) and also in reforming nuclei $(D, G)$. For comparison, images in $C$ and $F$ were not adjusted for brightness, contrast, or gamma. Embryo expressing full-length $\mathrm{Pbl}$ ( $p r d-G A L 4 / \mathrm{pbl}^{E P 3415}$ ) $(H)$ and wild-type embryos $(I, J)$ stained with anti-Pbl (red) and anti-lamin ( $H$, green), anti-anillin (I, green), or anti-Pnut (J, green). $\mathrm{Pbl}$ accumulation at the equator between dividing cells (arrow in $H$ ) parallels accumulation of anillin (arrow in I) and Pnut (arrow in I) beneath the cleavage furrow in which the contractile ring is assembled. $(K)$ Wild-type, $(L) p b l^{2}$ homozygous, and $(M) p b l^{5}$ homozygous embryos stained with anti-Pbl (red) and anti-lamin (green). Unlike in a wild-type embryo $(K)$, cycle 15 cells of the $p b 1^{2}$ embryo have greatly reduced levels of $\mathrm{Pbl}$ expression $(L)$ with few remaining speckles of staining scattered in nuclei of affected polyploid cells. Cycle 15 cells of $\mathrm{pbl}^{5}$ embryo $(M)$ have levels of nuclear Pbl staining comparable with wild type.
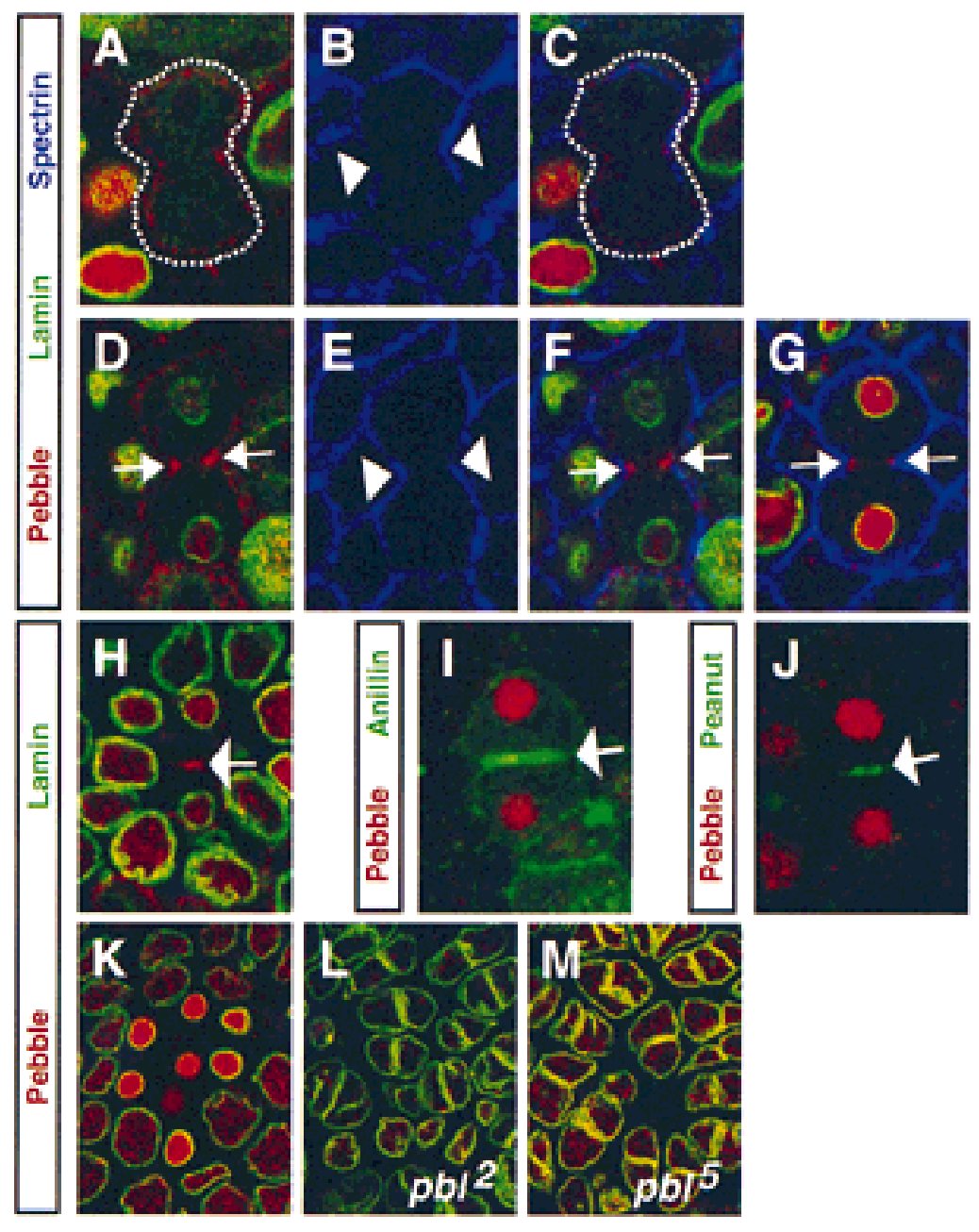
during cytokinesis. In addition, the levels of protein cycle during each cell cycle with the highest levels of $\mathrm{Pbl}$ in late telophase and interphase.

Embryos homozygous for the $p b l^{2}$ null allele as well as cytological deficiencies removing $p b l[D f(3 L) p b l-N R$ and $D f(3 L) 25]$ have greatly reduced levels of staining in cycle 15-16 interphase cells (Fig. 3 cf. L with $\mathrm{K}_{\text {; }}$ data not shown), which is likely to correspond to the remaining maternal contribution. In contrast, $p b 1^{5}$ embryos that carry the V531D missense mutation affecting a conserved valine (Fig. 2A,B) have protein levels comparable with wild type (Fig. 3M). It is likely that the reduction in the levels of cytoplasmic, but not nuclear $\mathrm{Pbl}$, is responsible for failure of cytokinesis in mitotic cycles 14-16, because we have never observed $\mathrm{Pbl}$ at the cortex or at the cleavage furrow during anaphase and telophase in cycle $14 \mathrm{pbl}$ mutant cells ( $p b 1^{2}$ and $p b 1^{5}$ alleles).

\section{Ectopic expression of amino-terminally truncated $\mathrm{Pbl}$ or Ect2 blocks cytokinesis}

The dramatic increase in Pbl levels at the onset of cytokinesis and localization of $\mathrm{Pbl}$ to the cleavage furrow suggest that $\mathrm{Pbl}$ may play a regulatory role in cytokinesis. As a protein, which presumably regulates the activity of Rho GTPases, Pbl may be required for the initiation of cytokinesis or may couple cytokinesis with the mitotic cycle. To investigate this hypothesis, we compared the effects of overexpression of full-length $\mathrm{Pbl}$ and of $\mathrm{Pbl}$ protein in which the BRCT domains and the NLS sequence were deleted ( $\Delta$ Pb1325-853 allele) (Fig. 2A).
The amino-terminal truncation in $\Delta \mathrm{Pbl} 325-853$ resembles a similar mutation in a number of mammalian RhoGEFs (for review, see Whitehead et al. 1997), including Ect2 (Miki et al. 1993), that results in the constitutive activation of their transforming potential. However, the amino-terminal sequences that are lost in different RhoGEFs do not share common domains. Hence, their role in controlling the activity of the full-length protein remains elusive.

Ectopic expression of full-length $\mathrm{Pbl}$ (with $p b 1^{E P 3415}$ or the $U A S-P b 1^{3.2}$ line) in stage 8-11 embryos with the paired-GAL4 (prd-GAL4) driver did not result in a detectable phenotype (Figs. 4A and $3 \mathrm{H}$ ). Although all cells in segments overexpressing $\mathrm{Pbl}$ had high levels of exogenous protein in their nuclei and cytoplasm, this did not interfere with cytokinesis, completion of mitosis (arrowhead in Fig. 4A), or viability. In contrast, expression of $\Delta \mathrm{Pbl} 325-853$ with the same driver led to $100 \%$ embryonic lethality. Most cells within the embryonic segments expressing $\Delta$ Pbl325-853 became multinucleate (Fig. 4B). This polyploid phenotype was caused by a failure of cytokinesis, because the cleavage furrow was not initiated (Fig. 4C), and, likewise, the contractile ring was not assembled (Fig. 4D; data not shown). We used the same approach to overexpress the amino-terminally truncated form of Ect2, $\Delta$ Ect2. As for $\Delta \mathrm{Pbl} 325-853$, ectopic expression of $\Delta$ Ect 2 resulted in the absence of the contractile ring and cleavage furrow, leading to formation of multinucleate cells (Fig. 4E,F), and lethality. In contrast, flies expressing full-length Ect2 exhibited no phenotype and were viable (data not shown).

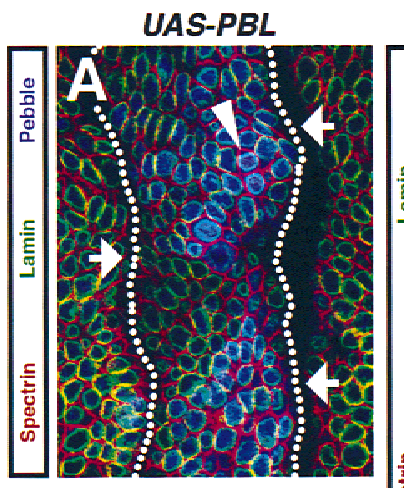

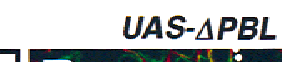

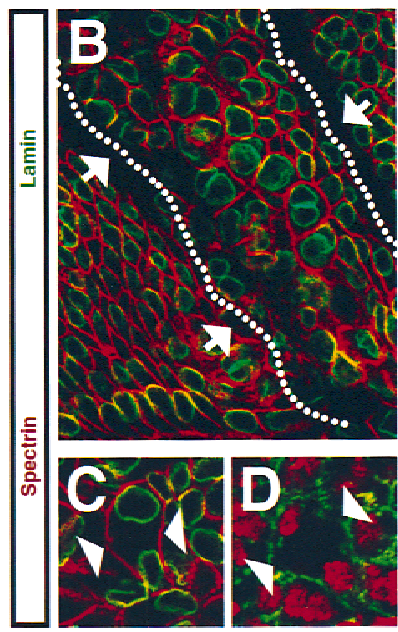

UAS- $\triangle E c t 2$

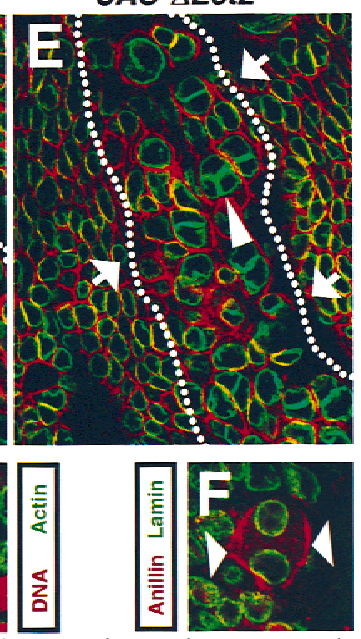

Figure 4. Ectopic expression of amino-terminally truncated $\mathrm{Pbl}$ or Ect2 blocks cytokinesis. (A) Stage $9 U A S-P_{b l}^{3.2} /+$, prdGAL4/+ embryo expressing full-length $\mathrm{Pbl}$ in a prd-like pattern stained with anti- $\alpha$ spectrin (red) to mark plasma membrane, anti-lamin (green) to reveal nuclei, and anti-Pbl (blue). Expression of full-length $\mathrm{Pbl}$ does not cause a phenotype during cell division, despite high levels of expression of exogenous $\mathrm{Pbl}$ in the affected segment (arrows). Note a pair of young postmitotic cells (arrowhead) with high levels of $\mathrm{Pbl}$ in the nuclei. High levels of exogenous $\mathrm{Pbl}$ and its apparent association with the nuclear envelope cause the nuclear laminae to appear blue. $(B, C)$ Stage $9 U A S_{-}$ $\triangle$ Pb1325-853 $3^{\text {S4-11 } /+, ~ p r d-G A L 4 /+~ e m b r y o ~}$ expressing amino-terminally truncated $\mathrm{Pbl}$ stained with anti- $\alpha$-spectrin (red) and anti-lamin (green). (D) A similar embryo stained with propidium iodide (red) to mark DNA and anti-actin to mark contractile ring (green). Expression of amino-terminally truncated Pbl leads to a block of cytokinesis. Most cells within the affected segment (arrows in $B$ ) become polyploid. During late anaphase, the cleavage furrow fails to initiate (arrowheads in $C)$ and actin does not redistribute to the equatorial region in which the contractile ring is assembled (arrowheads in $D$ ). The $\Delta \mathrm{Pbl} 325-$ 853 protein is cytoplasmic and cortical (data not shown). (E) Stage 9 prd-GAL4/UAS- $\Delta E c t 2^{S 2-1 A}$ embryo expressing amino-terminally truncated Ect2 stained with anti- $\alpha$-spectrin (red) and anti-lamin (green). (F) A similar embryo stained with anti-anillin (red) to mark the contractile ring and anti-lamin (green). Most cells within the segment expressing $\Delta$ Ect2 (arrows in $E$ ) become binucleate. Failure of cytokinesis during later divisions leads to formation of multinucleate cells (arrowhead in $E$ ). Similar to $\Delta \mathrm{Pbl} 325-853$, there are no signs of a cleavage furrow and anillin does not accumulate at the equatorial region in late anaphase (arrowheads in $F$ ). Dotted lines in $A, B$, and $E$ denote ectodermal segments expressing $\mathrm{Pbl}$ or Ect2. 
Thus, it appears that full-length $\mathrm{Pbl}$ (as well as Ect2) does not behave in vivo as an active protein, because it does not cause a cytokinetic phenotype when expressed in the embryonic ectoderm. This suggests that activation of the exchange activity of $\mathrm{Pbl}$ during cytokinesis may require some initiating event. In contrast, aminoterminally truncated $\mathrm{Pbl}$, when overexpressed in wildtype embryo, has a phenotype similar to lack of $p b l$. We propose that $\Delta \mathrm{Pbl}$ may behave as an activated protein competing with endogenous $\mathrm{Pbl}$ for a rate-limiting target protein (such as Rho GTPase), which results in an inappropriate activation of downstream effectors. Furthermore, the amino-terminal BRCT domains of Pbl, lacking in $\Delta \mathrm{Pbl}$ and known to be protein-protein interaction modules (Yamane et al. 1997; Chai et al. 1999), may be required for its regulation by an upstream signal. Such regulation may be essential for the spatial and temporal control of cytokinesis and for the coupling of signaling pathways initiating cytokinesis with other mitotic events.

\section{Identification of Rhol as a suppressor of $\mathrm{pbl}$}

In an effort to identify genes involved in the $\mathrm{Pbl}$ signaling pathway, we designed a genetic screen to isolate secondsite mutations interacting with $\mathrm{pbl}$. We used the GMRGAL4 driver which drives expression in all cells posterior to the morphogenetic furrow (Ellis et al. 1993) to express $\mathrm{Pbl}$ in the adult fly eye. Overexpression of $\mathrm{Pbl}$ (with the $U A S-P b l^{3.2}$ line) results in a dominant rough eye phenotype characterized by misshaped ommatidia, disrupted bristle distribution (Fig. 5B,G), misshapen rhabdomeres, and a significant increase in the number of pigment cells (Fig. 5 cf. L with K). In contrast, the external eye morphology of $U A S-P b 1^{3.2}$ flies was indistinguishable from wild type. Thus, overexpression of $\mathrm{Pbl}$ in the eye perturbs normal retinal development. Furthermore, the developing eye seems to be more sensitive than the embryo to overexpression of $\mathrm{Pbl}$, in which it does not cause a phenotype when expressed in ectodermal cells using the prd-GAL4 driver.
Figure 5. $p b l$ and Rhol interact in vivo. Scanning electron micrographs $(A-J)$ and methylene blue-stained transverse sections $(K-O)$ of wild-type $(A, F, K), G M R-G A L 4$, $U A S-P b 1^{3.2} /+(B, G, L), G M R-G A L 4, U A S-$ $\mathrm{Pbl}^{3.2} / \mathrm{Rho1}^{72 R} \quad(C, H, M)$, GMR-GAL4, $U A S-P b l \Delta D H 497-549^{5 B,}{ }^{6 A} /+(D, I, N)$, and GMR-GAL4, UAS-Pbl $D$ DH497-5495B, 6A/ $R h o 1^{72 R}(E, I, O)$ flies. Overexpression of $\mathrm{Pbl}$ in the eye induces a disruption of the ordered array of ommatidia $(B, G)$, as well as a disruption of the internal organization of rhabdomeres and a significant increase in the density and number of pigment cells $(L)$. These defects are suppressed dominantly by mutations in Rho1 $(C, H, M)$. Overexpression of $\mathrm{Pbl} \Delta \mathrm{DH} 497-549$ induces disruption of the ordered structure of the eye, with fusions of ommatidia, loss of many bristles $(D, I)$, and a decrease in the number of pigment cells $(N)$. These defects are strongly enhanced in a dominant fashion by mutation in Rho1 $(E, J, O)$. The eye phenotypes of $\mathrm{Pbl}$ and $\mathrm{Pbl} \Delta \mathrm{DH} 497-549$ are completely suppressed by the coexpression of the UASantisensePbl (data not shown). Flies were raised at $25^{\circ} \mathrm{C}$. Calibration bars: $(A-E) 100$ $\mu \mathrm{m}_{;}(F-O) 20 \mu \mathrm{m}$.
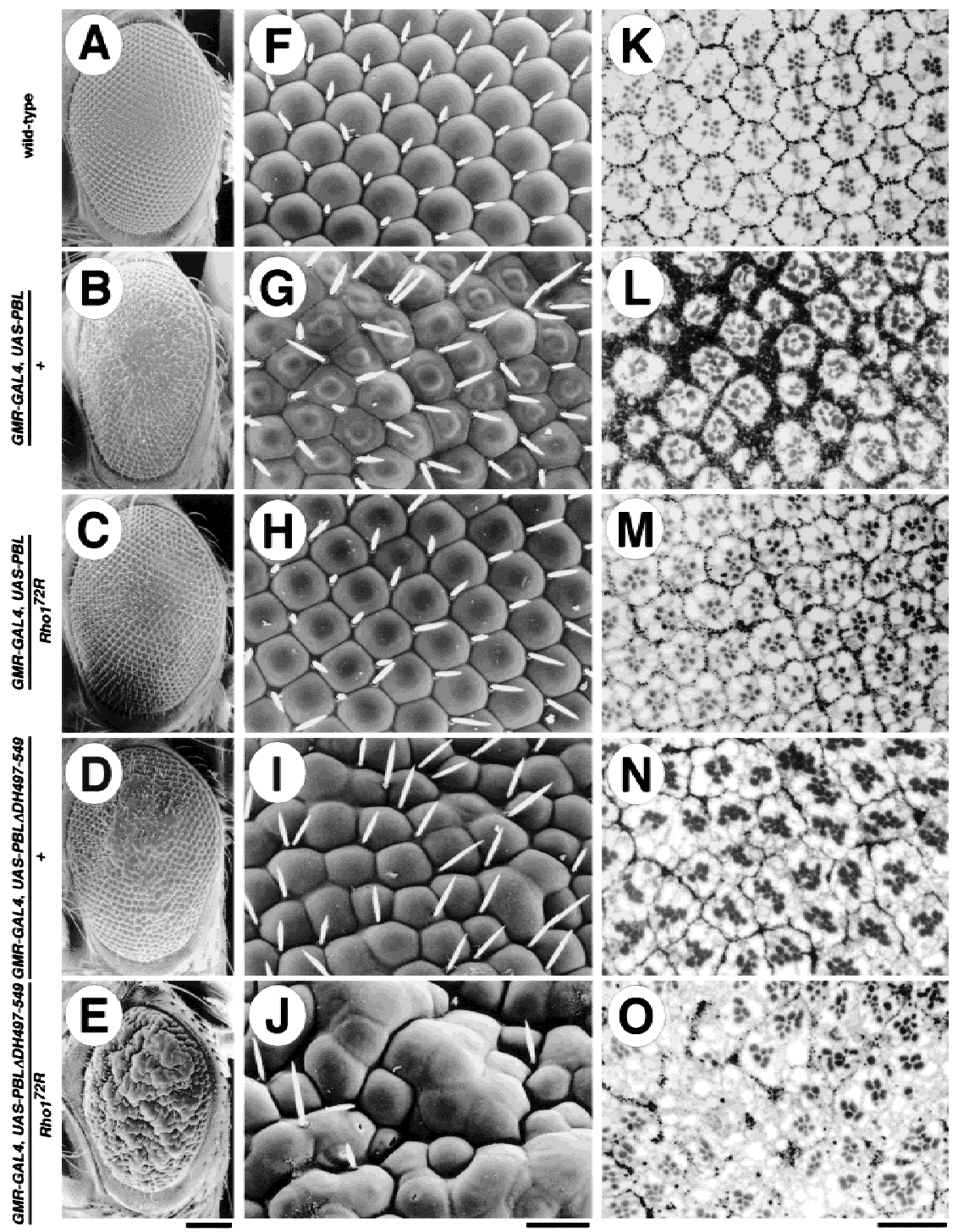
To identify dominant second-site modifiers of the rough eye phenotype caused by overexpression of $\mathrm{Pbl}$, the $G M R-P b l$ flies were crossed to males that carry deficiencies covering most of the II chromosome. The resulting $F_{1}$ progeny were examined for dominant enhancement or suppression of the rough eye phenotype. $D f(2 R) I p 8$ deficiency, identified as the only suppressor in the modifier screen, showed an almost complete suppression of the rough eye phenotype (data not shown). One of the genes uncovered by this deficiency is Rho1. To investigate the possibility that a mutation in Rho1 caused the suppression, we analyzed the phenotype of the progeny from a cross between the GMR-Pbl flies and null alleles of Rho1 (Strutt et al. 1997). Removal of a single copy of Rho1 dominantly suppressed the rough eye phenotype caused by overexpression of $\mathrm{Pbl}$ (Fig. $5 \mathrm{C}, \mathrm{H})$. Transverse sections showed rhabdomeres of more regular shape, number, and arrangement (Fig. 5 cf. M with L). In addition, the number and density of pigment cells is significantly decreased compared with the GMR$\mathrm{Pbl}$ flies. Hypomorphic alleles of Rho1 cause a similar, but much weaker suppression than $R$ hol null mutations (data not shown). In contrast, alleles of $C d c 42$ or a deficiency removing Rac1 did not suppress or enhance this phenotype (data not shown). These observations suggest that $p b 1$ interacts genetically with Rho1 and that the phenotypic suppression is specific for mutations in Rho1, but not for genes encoding other Rho family proteins, Cdc42 and Rac1.

Previously, it was shown that overexpression of Rhol in the eye results in disruption of both external and internal eye morphology (Hariharan et al. 1995). Mutations in $p b 1\left(p b 1^{1}, p b 1^{2}, p b 1^{3}, p b 1^{5}, p b 1^{P 81}, p b 1^{S 23}\right.$, and $p b 1^{V 58}$ alleles) caused a strong dominant suppression of the $G M R-R h o 1$-induced rough eye phenotype (data not shown). Because $p b l$ encodes a putative RhoGEF, these results suggest that a reduction in exchange factor activity in $\mathrm{pbl}$ alleles is responsible for the suppression of the GMR-Rho1-induced eye phenotype. Similarly, we propose that decreased levels of Rho1, a putative effector of $\mathrm{Pbl}$, account for suppression of the $G M R-P b l$-induced eye phenotype by Rho1 mutations.

To further characterize the genetic interaction between $\mathrm{pbl}$ and $R$ ho1, we generated a new deletion allele of $p b 1, P b l \Delta D H 497-549$, which affects the DH domain only (Fig. 2A). Site-directed mutagenesis in a number of RhoGEFs revealed that point mutations and deletions within the DH domain completely abolish exchange factor activity (Ron et al. 1991; Hart et al. 1994; Whitehead et al. 1995; Steven et al. 1998). Hence, to create an inactive form of $\mathrm{Pbl}$ that behaves as a dominant-negative protein, we introduced a short deletion (amino acids 497-549) removing the most highly conserved CR3 region (Soisson et al. 1998) within the DH domain. Mutations within this region dramatically diminish the $\mathrm{DH}$ domain function, suggesting that it is responsible for GTPase binding and nucleotide exchange activity. Expression of $\mathrm{Pbl} \Delta \mathrm{DH} 497-549$ in the eye with the GMRGAL4 driver results in a rough eye phenotype, with pronounced fusion of some ommatidia and a significant re- duction in the number of bristles (Fig. 5D,I). Transverse sections show a variation in the number of rhabdomeres per ommatidium and, unlike overexpression of the fulllength $\mathrm{Pbl}$, a decrease in the number of pigment cells (Fig. 5 cf. N with L). This phenotype is significantly enhanced in a dominant fashion by mutations in $p b l$ (data not shown). Similarly, mutations in Rho1 act as dominant enhancers of this phenotype, with a dramatic increase in the number of fused ommatidia and loss of many bristles (Fig. 5E,J). Transverse sections show a severe disorganization of the internal architecture of the eye, a complete absence of rhabdomeres in some regions of the eye, and a further decrease in the number of pigment cells (Fig. 5O). Because the Pbl $\Delta \mathrm{DH} 497-549$ protein is likely to be inactive (see below), we suggest that it may mimic the phenotype of hypomorphic alleles of $p b l$ by sequestering proteins (other than Rho1) that normally bind to or interact with endogenous $\mathrm{Pbl}$. As expected, mutations in Rho1 that interact genetically with $\mathrm{pbl}$ enhanced the phenotype of Pbl $\Delta$ DH497-549. In summary, pbl shows strong genetic interaction with Rho1, but not with Rac1 or $C d c 42$, indicating that $p b l$ and $R h o 1$ are in the same genetic pathway in vivo.

\section{Pbl and Rho1 proteins interact in a yeast two-hybrid assay}

Exchange factors for Rho proteins are known to activate their downstream targets through direct binding to Rho GTPases (Hart et al. 1994). Hence, the molecular basis for the observed genetic interaction between $p b l$ and Rho1 may be a physical interaction between $\mathrm{Pbl}$ and Rhol proteins. To test this hypothesis, we carried out a yeast two-hybrid assay. We constructed fusions of $\mathrm{Pbl}$ (full-length and amino-terminally truncated) as well as Drosophila Rho proteins, Rho1, Rac1, and Cdc42, with both the GAL4 DNA-binding domain (DBD) and GAL4 activation domain (AD). Plasmids were transformed in various combinations, and the resulting colonies were tested for the ability to activate HIS3 and lacZ reporters. Only colonies that carried plasmids expressing both $\mathrm{Pbl}$ (full-length or $\Delta \mathrm{Pbl} 325-853$, amino-terminally truncated $\mathrm{Pbl}$ ) and Rhol were able to grow on a medium that lacked His, Leu, and Trp (Fig. 6) suggesting that the HIS3 gene was induced. Furthermore, all His-positive colonies expressed $\beta$-galactosidase (Fig. 6C, sectors $a, d, e$, and f). In contrast, double transformants coexpressing $\mathrm{Pbl}$ and $\mathrm{Rac1}$, Cdc42, or $\mathrm{Pbl}$ instead of Rho1, failed to grow on a medium without His, Leu, and Trp (Fig. 6B, sectors b, c, $\mathrm{g}$, and $\mathrm{h}$ ). Therefore, we suggest that $\mathrm{Pbl}$ and Rhol proteins interact in vivo and that this interaction is specific for Rho1, but not for Rac1 or Cdc42. Furthermore, the $\mathrm{DH}$ domain, but not the amino terminus of Pbl (containing BRCT domains and NLS), is essential for this interaction, because it was abolished by a small deletion within the $\mathrm{DH}$ domain (Pbl $\Delta \mathrm{DH} 497-549$; Fig. 6A), but not by the amino-terminal truncation of $\mathrm{Pbl}(\Delta \mathrm{Pbl} 325-$ 853; Fig. 6B,C, sectors d,f). These results indicate that $\mathrm{Pbl}$ and Rhol form a protein complex in vivo, and that the basis for the genetic interaction between $p b l$ and 

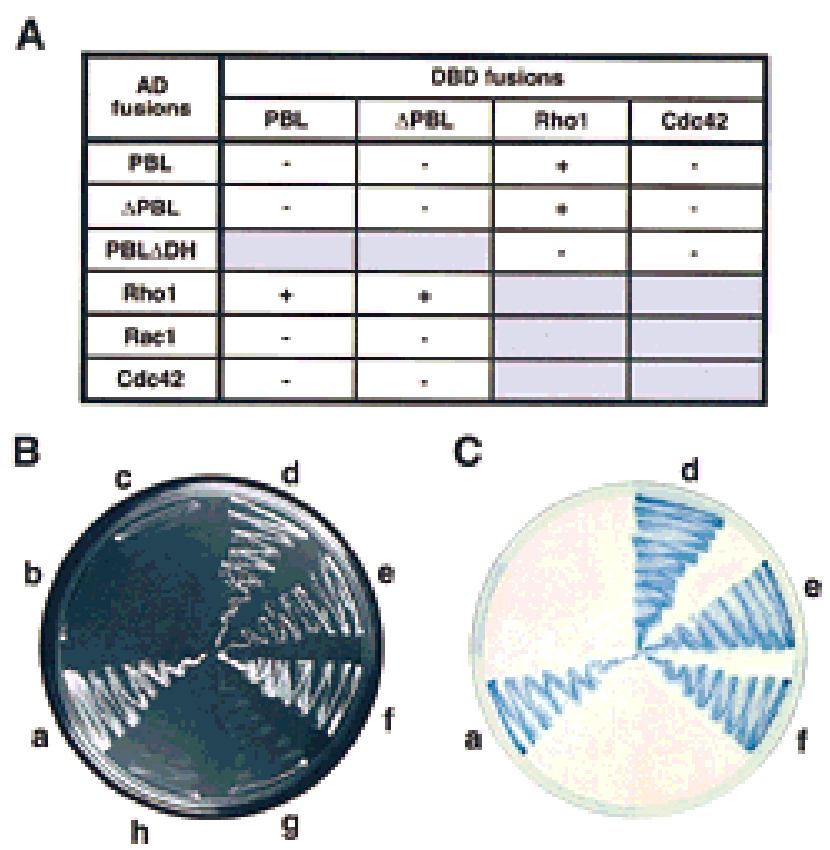

Figure 6. $\mathrm{Pbl}$ and Rhol proteins interact in a yeast two-hybrid assay. (A) Summary of pairwise interactions between $\mathrm{Pbl}$ and Drosophila Rho1, Rac1, and Cdc42. Minus and plus signs indicate the absence or presence of the activity of the GAL-HIS and $G A L-1 a c Z$ reporters. $(B, C)$ Representative results of assays for histidine $(B$, on SC-His-Leu-Trp) and $\beta$-galactosidase $(C$, on SC-Leu-Trp) activity. (a) pAS2/Pbl and pACT2/Rhol; $|b|$ pAS2/Pbl and pACT2/Rac1; (c) pAS2/Pbl and pACT2/Cdc42; (d) $\mathrm{pAS} 2 / \Delta \mathrm{Pbl}$ and $\mathrm{pACT} 2 / \mathrm{Rhol}$ (e) pAS2/Rhol and pACT2/ $\mathrm{Pbl}(f)$ pAS2/Rhol and $\mathrm{pACT} 2 / \Delta \mathrm{Pbl} ;(g) \mathrm{pAS} 2 / \mathrm{Cdc} 42$ and $\mathrm{pACT} 2 / \mathrm{Pbl}$; $(h) \mathrm{pAS} 2 / \mathrm{Pbl}$ and $\mathrm{pACT} 2 / \mathrm{Pbl}$. (AD) Activation domain; (DBD) DNA-binding domain; (Pbl) Pbl1-853; (Pbl $\Delta \mathrm{DH})$, $\mathrm{Pbl} \Delta \mathrm{DH} 497-549 ;(\Delta \mathrm{Pbl}) \Delta \mathrm{Pbl} 325-853$.

Rho1 may be a direct interaction between the two proteins.

\section{Rhol is required for cytokinesis}

To investigate the possibility that mutations in Rho1 cause defects during cell division, we stained Rho1 embryos with antibodies against lamin and $\alpha$-spectrin (Fig. 7A,B). Embryos homozygous for null alleles of Rho1 $\left(R h o 1^{72 O}\right.$ and $\left.R h o 1^{72 R}\right)$ showed many binucleate cells in the head region (Fig. 7A). Occasionally, we also observed a few polyploid cells in thoracic or abdominal segments (Fig. 7B). Although the latter phenotype was observed with low penetrance, we could never find binucleate ectodermal cells in wild-type embryos. The relatively weak phenotype caused by Rho1 mutations (unlike that of $p b l$ ) is most likely due to maternally provided Rhol protein. Thus, it appears that Rho1 is required for cytokinesis, and that decreased levels of Rhol may account for the observed phenotype in cytokinesis.

To further demonstrate the role of Rho1 in cytokinesis, we analyzed the effects of expression of a dominantnegative form of Rhol, Rho1 ${ }^{\mathrm{N} 19}$ (Strutt et al. 1997). It was shown that a dominant-negative form of H-Ras, $\mathrm{H}$ $\mathrm{Ras}^{\mathrm{N} 17}$, cannot interact with downstream target proteins (Farnsworth and Feig 1991; Feig 1999). In addition, H$\mathrm{Ras}^{\mathrm{N} 17}$ competes with normal H-Ras for binding to rasGEF, which results in formation of inactive H-Ras ${ }^{\mathrm{N} 17}$ rasGEF complexes and depletion of the pool of the endogenous rasGEF leading to a dominant-negative effect (Schweighoffer et al. 1993; Feig 1999). Therefore, a dominant-negative Rhol may produce a phenotype similar to or stronger than loss-of-function alleles of Rho1. Ectopic expression of Rho1 ${ }^{\mathrm{N} 19}$ creates a phenotype that is much worse than loss of zygotic Rho1 (Fig. $7 \mathrm{cf}$. C with A and B). Expression of Rho1 ${ }^{\mathrm{N} 19}$ in ectodermal stripes leads to a complete block of cytokinesis (Fig. 7D) leading to polyploidy of almost every cell within the affected segment. In contrast, expression of wild-type Rhol or dominantnegative Rac1 ( $\mathrm{Rac}^{\mathrm{N} 17}$ or $\mathrm{Racl}^{\mathrm{L} 89}$ ) did not affect cytokinesis or completion of mitosis (data not shown). Interestingly, coexpression of $\mathrm{Rhol}^{\mathrm{N} 19}$ and $\mathrm{Pbl}$ (unlike $\mathrm{Pbl}$ alone) results in the mislocalization of $\mathrm{Pbl}$ to the cell cortex in interphase and late mitotic cells (Fig. 7E,F) further indicating that the two proteins interact during cytokinesis. These results, together with other data, suggest that activation of the Rhol GTPase by Pbl, its putative exchange factor, is required for the initiation of cytokinesis, because mutations in either protein or overexpression of an inactive protein result in accumulation of multinucleate cells.

\section{Discussion}

$\mathrm{Pbl}$ is a putative exchange factor required for cytokinesis

Rho GTPases have been implicated in a variety of cellular processes and developmental events. Often the same Rho protein is involved in several interwoven signaling pathways activated within the same cell. The dynamic coordination of these molecular pathways during morphogenesis implies a complex level of regulation of Rho proteins, both spatially and temporally, by guanine nucleotide exchange factors and other molecules (Van Aelst and D'Souza-Schorey 1997). However, our knowledge about the biological functions of RhoGEFs is limited mainly to the studies of mammalian Dbl proteins and their roles in cell growth and oncogenic transformation (Whitehead et al. 1997). Genetic analyses in Drosophila and Caenorhabditis elegans have led to the identification of exchange factors required for axon guidance and cell migration (UNC-73; Steven et al. 1998), organization of actin cytoskeleton in synaptic terminals (SIF; Sone et al. 1997), and for coordination of cell shape changes during gastrulation (DRhoGEF2; Barrett et al. 1997; Häcker and Perrimon 1998).

The data presented here indicate that $\mathrm{Pbl}$ is the first identified putative RhoGEF specifically required for cytokinesis. First, mutations in all $p b l$ alleles result in the same phenotype-absence of a contractile ring and failure of cytokinesis. Second, during embryogenesis the highest levels of $\mathrm{Pbl}$ are found in dividing cells. Third, at 


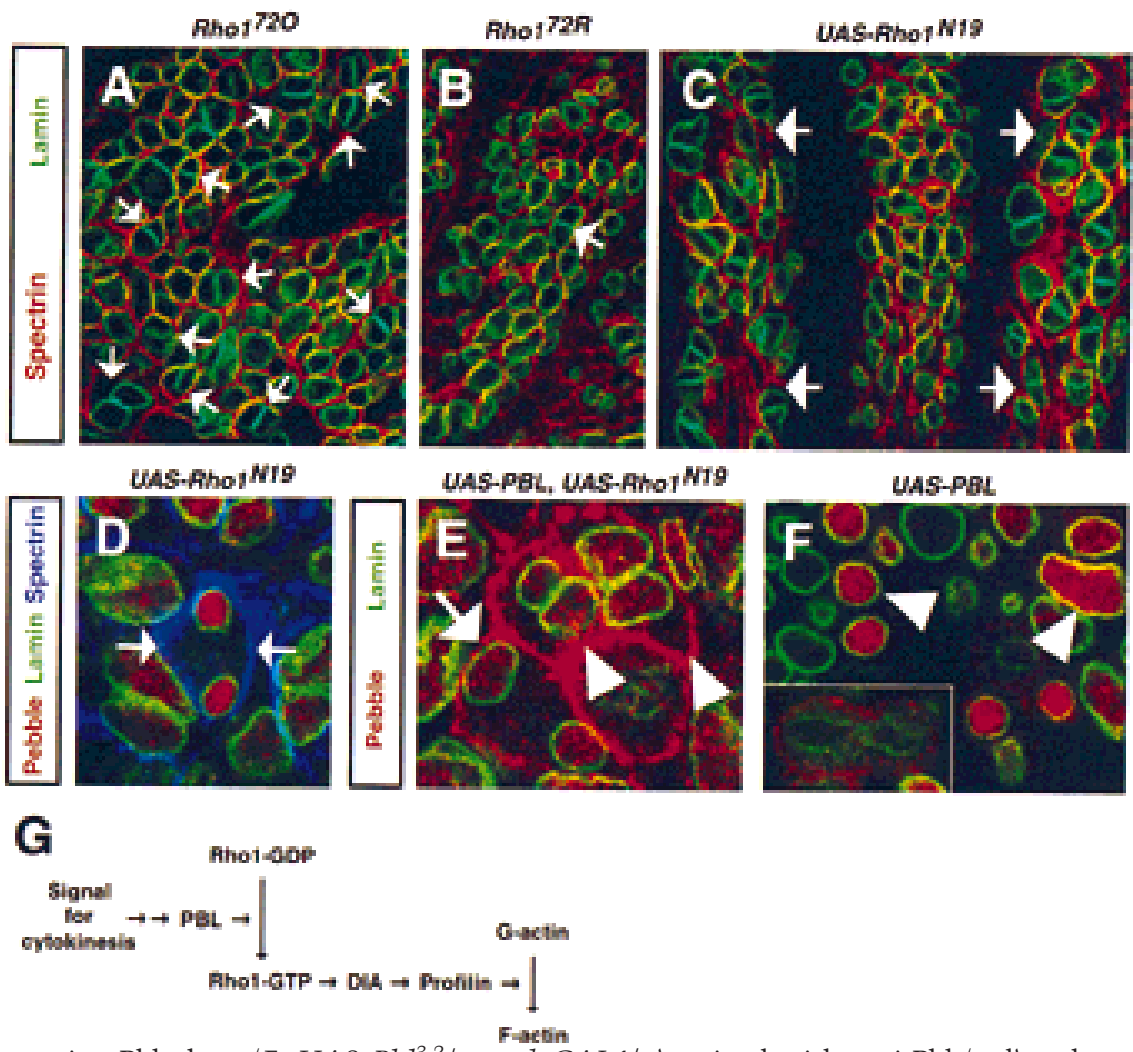

Figure 7. Mutations in Rho1 or expression of a dominant-negative Rhol abolish cytokinesis. Rho1 $1^{720}$ homozygous $(A$, stage 16$), R h o 1^{72 R}$ homozygous $(B$, stage 13) embryos, and an embryo expressing $\mathrm{Rhol}^{\mathrm{N} 19}$ in a paired-like pattern $\mid C, D$, $U A S-R h o 1^{\mathrm{N} 19} /+$, prd-GAL4/+, stage 9| stained with anti- $\alpha$-spectrin (red in $A-C$, blue in $D$ ) to mark plasma membrane, anti-lamin (green) to reveal nuclei, and anti-Pbl (red in $D) .(A, B)$ Null mutations in Rho1 block cytokinesis in affected cells. Many cells in the head region of the embryo $(A)$ become polyploid and contain two nuclei per cell (arrows). In addition, polyploid cells are found occasionally in thoracic or abdominal segments of Rho1 embryos (arrow in B, T2 segment). Homozygous Rho1 embryos were identified on the basis of their anterior open phenotype. $(C, D)$ Ectopic expression of a dominantnegative Rhol leads to formation of polyploid cells. Almost every cell within the affected segments (arrows in $C$ ) becomes binucleate. Despite high levels of nuclear $\mathrm{Pbl}$ in telophase, cleavage furrow fails (arrows in $D)$ and cytokinesis is not initiated. $(E, F)$ Embryo expressing $\mathrm{Pbl}$ and $\mathrm{Rhol}^{\mathrm{N} 19}(E, U A S-P b]^{3.2} /+$, prdGAL4/UAS-Rho1 ${ }^{\text {N19 }}$ ) and embryo ex pressing $\mathrm{Pbl}$ alone $\left(F, U A S-P b 1^{3.2} /+\right.$, prd $\left.-G A L 4 /+\right)$ stained with anti-Pbl (red) and anti-lamin (green). (E) Coexpression of $\mathrm{Pbl}$ and $\mathrm{Rho1}^{\mathrm{N} 19}$ results in accumulation of $\mathrm{Pbl}$ at the cortex in telophase (arrow) and especially in interphase (arrowheads) cells. (F) In contrast, distribution of $\mathrm{Pbl}$ in cells ectopically expressing $\mathrm{Pbl}$ alone is similar to wild-type cells with protein localized to the nuclei during interphase (arrowheads) and to the cortex in early anaphase (inset). (G) Proposed signaling pathway initiating cytokinesis. (Dia) Diaphanous; (F-actin) fibrous actin; (G-actin) globular actin; (Rhol-GDP) inactive GDP-bound Rho1; (Rho1-GTP) active GTP-bound Rhol. For details see Discussion.

the onset of cytokinesis, $\mathrm{Pbl}$ is associated with the cleavage furrow. As mitosis progresses, $\mathrm{Pbl}$, localized initially at the cortex and in the cytoplasm, accumulates at the cleavage furrow, where assembly of the contractile ring takes place. We propose that $\mathrm{Pbl}$ at the cleavage furrow is required for the initiation of cytokinesis by interacting with and regulating proteins involved in the assembly of the contractile ring. Although the highest levels of $\mathrm{Pbl}$ are found in late telophase and young postmitotic nuclei, nuclear $\mathrm{Pbl}$ does not seem to play a role in the initiation of cytokinesis. The accumulation of $\mathrm{Pbl}$ in telophase nuclei follows the initiation of the cleavage furrow and the beginning of the reassembly of the nuclear envelope and, hence, occurs too late in mitosis to be an instructive signal for cytokinesis. This conclusion is further supported by our observation that amino-terminally truncated $\mathrm{Pbl}, \Delta \mathrm{Pbl}$, lacking the NLS and localized to the cell cortex and cytoplasm is able to block cytokinesis. $\Delta \mathrm{Pbl}$ may compete with the endogenous $\mathrm{Pbl}$ at the cleavage furrow for Rhol or, possibly, other proteins that bind to $\mathrm{Pbl}$.

What is the function of nuclear $\mathrm{Pbl}$ ? The translocation of $\mathrm{Pbl}$ to the nuclei may be a regulatory mechanism to turn off the downstream signaling cascade by removing a RhoGEF from the cellular compartment in which the cascade was initiated. Alternatively, there may be two pools of $\mathrm{Pbl}$ protein-a cytoplasmic/cortical pool required for the initiation of cytokinesis and another pool targeted to nuclei in which $\mathrm{Pbl}$ plays some other role unrelated to cytokinesis.

\section{Pbl interacts specifically with Rho1}

Recent experimental data suggest that Rho proteins are required, in addition to their well-established roles in cell adhesion, cell motility, chemotaxis, and axon guidance, for the regulation of cytoskeletal events at the cleavage furrow during cytokinesis. Microinjection or expression of a Rho-specific inhibitor or activated forms of RhoA or Cdc42 as well as regulators (rho GDI; Kishi et al. 1993) or downstream effectors (Rho kinase; Yasui et al. 1998) of Rho proteins in sand dollar eggs (Mabuchi et al. 1993), Xenopus embryos (Drechsel et al. 1996), and mammalian cells (Dutarte et al. 1996; O'Connell et al. 1999) result in the uncoupling of mitosis from cytokinesis, regression of the cleavage furrow, and formation of multinucleate cells. However, genetic evidence supporting the role of Rho family proteins in cytokinesis is limited to the Dictyostelium racE gene that is required for cleavage furrow constriction and completion of cyto- 
kinesis (Gerald et al. 1998). Here, we provide in vivo evidence that in Drosophila, both Rhol and its putative exchange factor are required for the assembly of the contractile ring and, hence, initiation of cytokinesis. Mutations in both Rho1 and pbl result in a similar phenotype-absence of the contractile ring and formation of polyploid cells. We observed similar defects when we ectopically expressed a dominant-negative Rhol, $\mathrm{Rhol}^{\mathrm{N} 19}$. Drosophila Rho1 has been shown to be required for cellularization (Crawford et al. 1998), gastrulation (Barrett et al. 1997; Häcker and Perrimon 1998), dorsal closure (Harden et al. 1999), and generation of tissue polarity (Strutt et al. 1997), but not for cytokinesis. Our data suggest that the molecular basis of the genetic interaction between $\mathrm{pbl}$ and Rhol is a physical interaction between $\mathrm{Pbl}$ and Rho1 proteins, because the two proteins interact in a yeast two-hybrid assay. Both genetic data and two-hybrid assay results indicate that this interaction is specific for Rho1, but not Rac1 or Cdc42. This interaction presumably results in the activation of the Rhol GTPase by $\mathrm{Pbl}$ and induction of the signaling cascade that initiates the assembly of the contractile ring.

Our results illustrate the complexity of the intracellular signaling pathways involving Rho GTPases and their GEFs. In Drosophila, Rhol has also been identified as a putative effector of DRhoGEF2 (Barrett et al. 1997; Häcker and Perrimon 1998), indicating that Rhol is regulated by at least two RhoGEFs. Given the diversity of developmental roles of Rho1, one would expect that there is a complex hierarchy of molecules regulating its activity, both spatially and temporally, within a cell. Such differential regulation of Rhol by upstream signals may be achieved through tissue-specific expression of regulatory molecules (such as GEFs and GAPs) restricted to a particular developmental or cell cycle stage. An additional level of regulation within a cell can be achieved through subcellular compartmentalization of the molecular machinery (such as Rho effectors) required for the activation of distinct pathways mediated by Rho GTPases.

\section{Molecular pathway initiating cytokinesis: new insights}

Our observations suggest that $\mathrm{Pbl}$ is a key regulatory component of the signaling pathway initiating cytokinesis and therefore plays a unique role, different from other cytoskeletal and structural proteins known to be required for cytokinesis (Goldberg et al. 1998). First, unlike other proteins required for cytokinesis, the levels of $\mathrm{Pbl}$ protein cycle during each round of cell division. Second, $\mathrm{Pbl}$ accumulates at the cleavage furrow at the time when cytokinesis is initiated. Third, $\mathrm{Pbl}$ is a putative RhoGEF and our knowledge about mammalian RhoGEFs (Whitehead et al. 1997) clearly implicates them in the regulation of signaling pathways involving Rho GTPases. Fourth, mutations within the catalytic DH domain inactivate $\mathrm{Pbl}$ function ( $p b 1^{5}$ allele; Figs. $2 \mathrm{~B}$ and $3 \mathrm{M}$ ) and

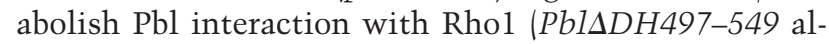
lele; Fig. 6A). In addition, ectopic expression of
$\mathrm{Pbl} \Delta \mathrm{DH} 497-549$ in the embryo or in the eye imaginal disk blocks cytokinesis and results in the formation of polyploid cells (data not shown).

The data presented here together with earlier observations allow us to propose a signaling pathway required for cytokinesis (Fig. 7G). We suggest that activation of Rhol GTPase by $\mathrm{Pbl}$ is required for initiation of a molecular pathway leading to assembly of a contractile ring. Such activation is likely to be achieved through direct binding of $\mathrm{Pbl}$ and Rhol at the cleavage furrow. This is consistent with data from other species, in which Rho proteins have been shown to localize to the plasma membrane or cytosol in resting cells, but to translocate to the cleavage furrow and midbody during cytokinesis (Adamson et al. 1992; Takaishi et al. 1995; Nishimura et al. 1998). Pbl has a similar distribution during mitosis, being initially cortical but accumulating at the cleavage furrow at the onset of cytokinesis. Significantly, coexpression of $\mathrm{Pbl}$ and a dominant-negative form of Rhol results in the accumulation of $\mathrm{Pbl}$ at the cell cortex in late mitotic cells, suggesting that the two proteins interact during cytokinesis.

Interaction of Rhol with its effectors is likely to occur at the mouse Diaphanous (Dia) furrow as suggested previously for mouse RhoA and p140mDia, a formin-related protein required for cytokinesis (Watanabe et al. 1997). Both p140mDia and its Drosophila homolog localize to the cleavage furrow during cytokinesis (Watanabe et al. 1997; Wasserman 1998; Field et al. 1999). Furthermore, mutations in dia result in the absence of a contractile ring (Giansanti et al. 1998) and failure of cytokinesis (Castrillon and Wasserman 1994). Interestingly, null alleles of dia dominantly suppress the rough eye phenotype of the GMR-Rho1 and GMR-Pbl flies, but domi-

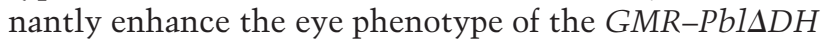
flies (data not shown), suggesting that the three genes are in the same pathway. In addition, ectopic expression of activated Rho1, Rho1 ${ }^{\mathrm{V} 14}$, but not wild-type Rho1, abolishes cytokinesis (data not shown). Because mouse p140mDia interacts preferentially with activated RhoA, RhoA $^{\mathrm{V} 14}$, but not with wild-type RhoA (Watanabe et al. 1997), we suggest that Rho1 v14 blocks cytokinesis by titrating out one of its limiting downstream effectors, such as Dia, required for the initiation of cytokinesis. Mouse and Drosophila Dia (Watanabe et al. 1997; Wasserman 1998), as well as other formin-related proteins implicated in cytokinesis [Bnilp in Saccharomyces cerevisiae (Evangelista et al. 1997) and cdc12p in Schizosaccharomyces pombe (Chang et al. 1997)] bind profilin, an actin-binding protein that regulates F-actin polymerization, in vitro and in vivo. In Drosophila, mutations in profilin [encoded by the chic gene] block the assembly of a contractile ring during meiotic cytokinesis (Giansanti et al. 1998), and in fission yeast, mutations in both genes-cdc12 (formin) and cdc3 (profilin) show a synthetic lethal genetic interaction (Chang et al. 1997).

In conclusion, we propose a linear signaling pathway linking a RhoGEF with the actin cytoskeleton and, hence, the actomyosin contractile ring (Fig. 7G). All of the components of this pathway have been implicated in 
cytokinesis and were shown to localize to the cleavage furrow during cytokinesis in Drosophila or other organisms. Furthermore, all of the proteins in the pathway interact in vivo or in vitro with their neighboring partners. We conclude that the activation of Rhol by $\mathrm{Pbl}$ is likely to be an initiating event for the assembly of the contractile ring at the onset of cytokinesis. Identification of upstream components of this pathway will shed light on how cytokinesis is coordinated with the mitotic cycle and on the nature of the signal required for cytokinesis.

\section{Materials and methods}

\section{Fly stocks}

Alleles of $p b l$ used in this study are $p b 1^{1}, p b 1^{2}, p b 1^{3}, p b 1^{5}$ (Jürgens et al. 1984), $p b 1^{p 81}, p b I^{S 23}, p b l^{V 58}$ (J.B. Skeath and C.Q. Doe, pers. comm.), pbl ${ }^{\text {So08320 }}$, pbl $^{\text {SO54203 }}$ (Salzberg et al. 1997), $\mathrm{P}\{P Z\} 1(3) 09645^{09645}$, and EP(3)3415 (Berkeley Drosophila Genome Project, unpubl.) that we renamed $p b 1^{09645}$ and $p b 1^{E P 3415}$, respectively. $p b 1^{09645}$ and $p b 1^{E P 3415}$ are revertible P-element insertions that fail to complement other alleles of $p b l$ and map to 66B1-5 and 66A20-22, respectively. The $C d c 42^{3}$ and $C d c 42^{4}$ alleles (Fehon et al. 1997) and $R h o 1^{72 O}$ and $R h o 1^{72 R}$ alleles (Strutt et al. 1997) were obtained from R. Fehon and M. Mlodzik, respectively. The $D f(3 L)$ Ar14-8 deficiency was used as an allele of Rac1. The UAS-Rho1 ${ }^{N 19}$ transgenic lines (Strutt et al. 1997) and UAS-Rho1-Sph lines carrying a wild-type Rho1 transgene were kindly provided by M. Mlodzik. The UAS-Rac1 ${ }^{N 17}$ and UAS$R a c 1^{L 89}$ lines (Luo et al. 1994) were received from L. Luo. The GMR-Rho $1^{1}$ Rho $1^{3}$ flies (Hariharan et al. 1995) were obtained from J. Settleman. The $\mathrm{dia}^{2}$ allele (Castrillon and Wassermant 1994) was provided by S. Wasserman. The published breakpoints of the $D f(2 R) J p 8$ deficiency (52F5-9; 53A1) (FlyBase: http://flybase.bio.indiana.edu// are incorrect, because it fails to complement $R$ ho1 mutations that map at 52E3-6. Canton-S was used as the wild-type strain.

Histology, scanning electron microscopy, immunohistochemistry, and confocal microscopy

For histological analyses, adult eyes were incubated in periodate/lysine/paraformaldehyde for $30 \mathrm{~min}$, fixed in $2.5 \%$ glutaraldehyde/0.1M sodium phosphate $(\mathrm{pH} 7.2)$ overnight, postfixed in $2 \%$ osmium tetroxide, washed in water, and dehydrated in acetone. Specimens were mounted in epoxy resin, sectioned at $2 \mu \mathrm{m}$, and stained with methylene blue. For scanning electron microscopy, adult eyes were dehydrated through an acetone series, dried in a critical point drier, coated with gold/palladium in a vacuum evaporator, and viewed with a field emission scanning electron microscope (Phillips).

The following primary antibodies were used: anti-actin $(\mathrm{C} 4$, 1:20000, ICN Biomedicals), anti-anillin (1:1000; Field and Alberts 1995), anti-lamin A (T47, 1:20; Frasch et al. 1986), antilamin Dm0 (611A3A6, 1:20-1:50; Harel et al. 1989), anti-lamin Dm0 (Rb294, 1:50; Fisher and Smith 1988), anti-Peanut (4C9H4, partially purified immunoglobulin, 1:20, Developmental Studies Hybridoma Bank, University of Iowa, Iowa City; Neufeld and Rubin 1994), anti-phospho-histone H3 (1:1000, Upstate Biotechnology; Hendzel et al. 1997), and anti- $\alpha$-spectrin (Ab\#354, 1:400; Byers et al. 1987). Secondary antibodies used were Cy3 (1:500), Cy5 (1:250, Jackson ImmunoResearch Laboratories), Alexa488 (1:400, Molecular Probes) IgG $(\mathrm{H}+\mathrm{L})$ conjugates, and biotinylated IgG $(\mathrm{H}+\mathrm{L})$ (1:200, Vector Laboratories) with streptav-
idin-Cy5 conjugate (1:1000, Jackson ImmunoResearch Laboratories). DNA was stained with $100 \mu \mathrm{g} / \mathrm{ml}$ propidium iodide (Sigma). Specimens were mounted in Vectashield mounting medium (Vector Laboratories) and analyzed with the MRC-1024 confocal imaging system (Bio-Rad). Images were processed with LaserSharp 3.0 software (Bio-Rad).

\section{Cloning of $\mathrm{pbl}$ and sequencing of point mutations}

Genomic sequences flanking $\mathrm{pbl}^{\mathrm{S008320}}$ and $\mathrm{pbl}^{5054203} \mathrm{P}$-element insertions were isolated by plasmid rescue. Genomic fragments from the 0.8-kb A6 EcoRI (from $\mathrm{pbl}^{\mathrm{S008320}}$ ) and 2.8-kb B1 $\mathrm{BamHI}$ (from $\mathrm{pbl}^{\mathrm{SO54203}}$ ) rescues were used to isolate the $1 \mathrm{~A}$ (3140 bp) and 1C (1642 bp) cDNAs from an embryonic (9-12 hr) cDNA library (Zinn et al. 1988). Both cDNAs map to 66B, detect two transcripts of 4.0 and $5.5-\mathrm{kb}$ on Northern blots, which are expressed throughout Drosophila development, have the same expression pattern during embryonic development, and correspond to the same gene. Alignment of the sequences of plasmid rescues from pbl ${ }^{09645}$ (GenBank accession no. AQ073344), $p b 1^{E P 3415}$ (GenBank accession no. AQ254711), pbl $1^{5054203}$, and

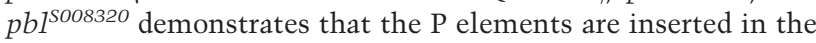
5' UTR, 492, 457, and 149 nucleotides upstream of the AUG start codon, and in the ORF of the 1A cDNA, respectively. The $1 \mathrm{~A}$ pbl cDNA encodes a predicted ORF of 853 amino acids.

To sequence $p b 1$ EMS alleles, total RNA isolated from $\mathrm{pbl} /$ TM3 flies was used as a template for first strand cDNA synthesis (Superscript II, GIBCO BRL) with a primer complementary to the $3^{\prime}$ end of the $p b l$ coding sequence $\left(5^{\prime}\right.$-CGCGGATCCTCAGCTCTAAATGCGGCCCACAAC-3'). The entire coding sequence was amplified (Elongase, GIBCO BRL) with the same $3^{\prime}$ primer and the $5^{\prime}$ primer $\left(5^{\prime}\right.$-CGCGGATCCTGATGGAAATGGAGACCATTGAAGAG-3') and cloned subsequently in BamHI sites of pBluescript KS+ (Stratagene). Two independent mutant clones were isolated and sequenced for each $p b l$ allele. Natural polymorphisms made it possible to distinguish mutant clones from those derived from the balancer chromosome. The presence of the CAG to TAG mutation in the $p b l^{2}$ allele disrupting the PstI site was confirmed by Southern analysis using the 2-kb EcoRI-BglII fragment of the $1 \mathrm{~A} p b 1 \mathrm{cDNA}$ as a probe.

\section{Generation of antibodies to $\mathrm{Pbl}$}

A 2.4-kb EagI fragment of the 1A pbl cDNA corresponding to amino acids 96-853 was cloned into pET-28b(+) (Novagen) to express amino-terminally tagged His fusion protein. The induced protein was resolved on an SDS-polyacrylamide gel, and protein-containing acrylamide fragments were homogenized and injected into rats and guinea pigs. The following observations suggest that the four immune sera produced (rat R8 and R9 and guinea pig GP14 and GP15) are specific. First, all antibodies give the same pattern of staining in wild-type embryos and on Western recognize a $120-\mathrm{kD}$ protein and several bands of lower molecular mass that are likely to be degradation products. Second, the immune sera recognize an ectopically expressed protein. Third, the antigen detected by immune sera is mislocalized, exhibits decreased levels, or is lacking in pbl mutant embryos. The $\mathrm{R} 8$ rat anti-Pbl immune serum was used at 1:800-1: 1000 for indirect immunofluorescence and at 1:5000 for Western.

\section{Generation of $\mathrm{pbl}$ and ect2 transgenic lines}

The 1A pbl cDNA was cloned in forward or reverse orientation into pUAST to generate $U A S-P b l$ and $U A S$-antisensePbl transgenic lines, respectively. A fragment of the $p b l$ cDNA corre- 
sponding to amino acids 325-853 was amplified (Elongase, GIBCO BRL) and cloned into pUAST to generate UAS$\triangle P b 1325-853$ transgenic lines. To generate UAS-PblDDH497549 transgenic lines, 1.94-kb EcoRI-ScaI and 1.04-kb SpeI/filledin)-EcoRI fragments of the $1 \mathrm{~A} p b l \mathrm{cDNA}$ were coligated with pUAST digested (Miki et al. 1993) with EcoRI. Full-length ect2 cDNA (from pCEV27-ect2-F; and amino-terminally truncated ect2 cDNA (from p3N-11/ATG; Miki et al. 1993) were cloned into pUAST to generate UAS-Ect2 and UAS-DEct2 transgenic lines, respectively. To assess the relative strength of different lines with independent insertions of a transgene, they were crossed to GMR-GAL4, dpp-GAL4, and 32B-GAL4 drivers, and adult flies were analyzed for abnormalities in eye and/or wing development. The phenotypes ranged from lack of visible defects to $100 \%$ pupal lethality. For overexpression studies, the following transgenic lines were selected: $U A S-P b 1^{3.2}, U A S-$

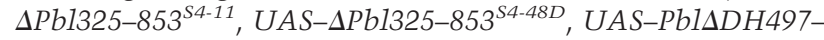
$549^{5 B}, U A S-P b 1 \Delta D H 497-549^{6 A}, U A S-E c t 2^{S 3-19}, U A S-\Delta E c t 2^{S 2-}$ $1 A$, and $U A S-\Delta E c t 2^{S 2-3}$. The RG1 prd-GAL4 driver was used for ectopic expression of proteins in stage 8-11 embryos. $G M R-P b 1 \quad\left(G M R-G A L 4, U A S-P b 1^{3.2}\right)$ and GMR-PblDDH (GMR-GAL4, UAS-Pbl $\Delta D H 497-549^{5 B},{ }^{6 A}$ ) are recombinant II chromosomes carrying the GMR-GAL4 driver and one $U A S-P b l$ transgene (from line 3.2) and two copies of the UAS-Pbl $\triangle D H 497-549$ transgene (from lines 5B and 6A), respectively. Expression of $p b l$ transgenes in eye imaginal disks and in embryos was confirmed immunohistochemically.

\section{Yeast two-hybrid interaction assay}

ORFs of Rho1, Rac1, Cdc42, $\Delta$ Pbl325-853, PblaDH497-549, and $1 \mathrm{~A} \mathrm{pbl} \mathrm{cDNA} \mathrm{were} \mathrm{cloned} \mathrm{into} \mathrm{pAS2} \mathrm{and} \mathrm{pACT2} \mathrm{to} \mathrm{create}$ GAL4 DBD and AD fusions, respectively. Plasmids were cotransformed in various combinations in yeast strain PJ69-4A (James et al. 1996), and transformants were selected on SC-His-Leu-Trp medium. $\mathrm{His}^{+}$colonies were tested for $\beta$-galactosidase activity on SC-Leu-Trp medium.

\section{Acknowledgments}

We thank D. Branton, C. Doe, R. Fehon, C. Field, P. Fisher, D. Glover, Y. Gruenbaum, Y. Hotta, L. Luo, T. Miki, M. Mlodzik, C. Nüsslein-Volhard, J. Settleman, S. Wasserman, and K. Zinn for providing reagents. We thank Manzoor A. Bhat, David M. Glover, Scott Goode, Anthony L. Lau, and Shelley Sazer for critically reviewing the manuscript and Michelle Coombe for excellent technical assistance. This work was supported in part by the Australian Research Council. L.O. and L.P. are supported by the University of Adelaide Postgraduate Award and an Australian Postgraduate Award, respectively. H.J.B. is Associate Investigator of the Howard Hughes Medical Institute.

The publication costs of this article were defrayed in part by payment of page charges. This article must therefore be hereby marked 'advertisement' in accordance with 18 USC section 1734 solely to indicate this fact.

\section{Note}

The GenBank accession number for the sequence of $p b l$ described in this paper is AF136492.

\section{References}

Adamson, P., H.F. Paterson, and A. Hall. 1992. Intracellular localization of the P21 ${ }^{\text {rho }}$ proteins. J. Cell Biol. 119: 617-627.
Barrett, K., M. Leptin, and J. Settleman. 1997. The Rho GTPase and a putative RhoGEF mediate a signaling pathway for the cell shape changes in Drosophila gastrulation. Cell 91: 905915.

Bork, P., K. Hofmann, P. Bucher, A.F. Neuwald, S.F. Altschul, and E.V. Koonin. 1997. A superfamily of conserved domains in DNA damage-responsive cell cycle checkpoint proteins. FASEB T. 11: 68-76.

Byers, T.J., R. Dubreuil, D. Branton, D.P. Kiehart, and L.S. Goldstein. 1987. Drosophila spectrin. II. Conserved features of the alpha-subunit are revealed by analysis of cDNA clones and fusion proteins. J. Cell Biol. 105: 2103-2110.

Callebaut, I. and J.P. Mornon. 1997. From BRCA1 to RAP1: A widespread BRCT module closely associated with DNA repair. FEBS Lett. 400: 25-30.

Castrillon, D.H. and S.A. Wasserman. 1994. diaphanous is required for cytokinesis in Drosophila and shares domains of similarity with the products of the limb deformity gene. Development 120: 3367-3377.

Chai, Y., J. Cui, N. Shao, E.S.P. Reddy, and V.N. Rao. 1999. The second BRCT domain of BRCA1 proteins interacts with p53 and stimulates transcription from the $\mathrm{p} 21^{\mathrm{WAF} 1 / \mathrm{CIP} 1}$ promoter. Oncogene 18: 263-268.

Chang, F., D. Drubin, and P. Nurse. 1997. cdc12p, a protein required for cytokinesis in fission yeast, is a component of the cell division ring and interacts with profilin. J. Cell Biol. 137: 169-182.

Crawford, J.M., N. Harden, T. Leung, L. Lim, and D.P. Kiehart. 1998. Cellularization in Drosophila melanogaster is disrupted by the inhibition of rho activity and the activation of Cdc42 function. Dev. Biol. 204: 151-164.

Drechsel, D.N., A.A. Hyman, A. Hall, and M. Glotzer. 1996. A requirement for Rho and $\mathrm{Cdc} 42$ during cytokinesis in Xenopus embryos. Curr. Biol. 7: 12-23.

Dutartre, H., J. Davoust, J.P. Gorvel, and P. Chavrier. 1996. Cytokinesis arrest and redistribution of actin-cytoskeleton regulatory components in cells expressing the Rho GTPase CDC42Hs. J. Cell Sci. 109: 367-377.

Ellis, M.C., E.M. O'Neill, and G.M. Rubin. 1993. Expression of Drosophila glass protein and evidence for negative regulation of its activity in non-neuronal cells by another DNAbinding protein. Development 119: 855-865.

Evangelista, M., K. Blundell, M.S. Longtine, C.J. Chow, N. Adames, J.R. Pringle, M. Peter, and C. Boone. 1997. Bnilp, a yeast formin linking cdc42p and the actin cytoskeleton during polarized morphogenesis. Science 276: 118-122.

Fares, H., M. Peifer, and J.R. Pringle. 1995. Localization and possible functions of Drosophila septins. Mol. Biol. Cell 6: $1843-1859$.

Farnsworth, C.L. and L.A. Feig. 1991. Dominant inhibitory mutations in the $\mathrm{Mg}(2+)$-binding site of RasH prevent its activation by GTP. Mol. Cell. Biol. 11: 4822-4829.

Fehon, R.G., T. Oren, D.R. LaJeunesse, T.E. Melby, and B.M. McCartney. 1997. Isolation of mutations in the Drosophila homologues of the human Neurofibromatosis 2 and yeast CDC42 genes using a simple and efficient reverse-genetic method. Genetics 146: 245-252.

Feig, L.A. 1999. Tools of the trade: Use of dominant-inhibitory mutants of Ras-family GTPases. Nat.Cell Biol. 1: E25-E27.

Field, C.M. and B.M. Alberts. 1995. Anillin, a contractile ring protein that cycles from the nucleus to the cell cortex. J. Cell Biol. 131: 165-178.

Field, C.M., O. Al-Awar, J. Rosenblatt, M.L. Wong, B. Alberts, and T.J. Mitchison. 1996. A purified Drosophila septin complex forms filaments and exhibits GTPase activity. I. Cell Biol. 133: 605-616. 
Field, C., R. Li, and K. Oegema. 1999. Cytokinesis in eukaryotes: A mechanistic comparison. Curr. Opin. Cell Biol. 11: $68-80$.

Fisher, P.A. and D.E. Smith. 1988. Affinity purification of antibodies using antigens immobilized on solid supports. Biochem. Soc. Trans. 16: 134-138.

Frasch, M., D.M. Glover, and H. Saumweber. 1986. Nuclear antigens follow different pathways into daughter nuclei during mitosis in early Drosophila embryos. J. Cell Sci. 82: 155172.

Gerald, N., J. Dai, H.P. Ting-Beall, and A. De Lozanne. 1998. A role for Dictyostelium racE in cortical tension and cleavage furrow progression. J. Cell Biol. 141: 483-492.

Giansanti, M.G., S. Bonaccorsi, B. Williams, E.V. Williams, C. Santolamazza, M.L. Goldberg, and M. Gatti. 1998. Cooperative interactions between the central spindle and the contractile ring during Drosophila cytokinesis. Genes \& Dev. 12: 396-410.

Giansanti, M.G., S. Bonaccorsi, and M. Gatti. 1999. The role of anillin in meiotic cytokinesis of Drosophila males. J. Cell Sci. 112: 2323-2334.

Goldberg, M.L., K.C. Gunsalus, R.E. Karess, and F. Chang. 1998. Cytokinesis. In Dynamics of cell division (ed. S.A. Endow and D.M. Glover), pp. 270-316. Oxford University Press, London, UK.

Gunsalus, K.C., S. Bonaccorsi, E. Williams, F. Verni, M. Gatti, and M.L. Goldberg. 1995. Mutations in twinstar, a Drosophila gene encoding a cofilin/ADF homologue, result in defects in centrosome migration and cytokinesis. I. Cell Biol. 131: 1243-1259.

Häcker, U. and N. Perrimon. 1998. DRhoGEF2 encodes a member of the Dbl family of oncogenes and controls cell shape changes during gastrulation in Drosophila. Genes \& Dev. 12: 274-284.

Hall, A. 1998. Rho GTPases and the actin cytoskeleton. Science 279: $509-514$.

Harden, N., M. Ricos, Y.M. Ong, W. Chia, and L. Lim. 1999. Participation of small GTPases in dorsal closure of the Drosophila embryo: Distinct roles for Rho subfamily proteins in epithelial morphogenesis. J. Cell Sci. 112: 273-284.

Harel, A., E. Zlotkin, S. Nainudel-Epszteyn, N. Feinstein, P.A. Fisher, and Y. Gruenbaum. 1989. Persistence of major nuclear envelope antigens in an envelope-like structure during mitosis in Drosophila melanogaster embryos. J. Cell Sci. 94: 463-470.

Hariharan, I.K., K.Q. Hu, H. Asha, A. Quintanilla, R.M. Ezzell, and J. Settleman. 1995. Characterization of rho GTPase family homologues in Drosophila melanogaster: Overexpressing Rhol in retinal cells causes a late developmental defect. EMBO J. 14: 292-302.

Hart, M.J., A. Eva, D. Zangrilli, S.A. Aaronson, T. Evans, R.A. Cerione, and Y. Zheng. 1994. Cellular transformation and guanine nucleotide exchange activity are catalyzed by a common domain on the $d b l$ oncogene product. J. Biol. Chem. 269: 62-65.

Hendzel, M.J., Y. Wei, M.A. Mancini, A. Van Hooser, T. Ranalli, B.R. Brinkley, D.P. Bazett-Jones, and C.D. Allis. 1997. Mitosis-specific phosphorylation of histone $\mathrm{H} 3$ initiates primarily within pericentromeric heterochromatin during G2 and spreads in an ordered fashion coincident with mitotic chromosome condensation. Chromosoma 106: 348-360.

Hime, G. and R. Saint. 1992. Zygotic expression of the pebble locus is required for cytokinesis during the postblastoderm mitoses of Drosophila. Development 114: 165-171.

James, P., J. Halladay, and E.A. Craig. 1996. Genomic libraries and a host strain designed for highly efficient two-hybrid selection in yeast. Genetics 144: 1425-1436.

Jürgens, G., E. Wieschaus, C. Nüsslein-Volhard, and H. Kluding. 1984. Mutations affecting the pattern of the larval cuticle in Drosophila melanogaster. II. Zygotic loci on the third chromosome. Wilhelm Roux's Arch. Dev. Biol. 193: 283-295.

Karess, R.E., X. Chang, K.A. Edwards, S. Kulkarni, I. Aguilera, and D.P. Kiehart. 1991. The regulatory light chain of nonmuscle myosin is encoded by spaghetti-squash, a gene required for cytokinesis in Drosophila. Cell 65: 1177-1189.

Kishi, K., T. Sasaki, S. Kuroda, T. Itoh, and Y. Takai. 1993. Regulation of cytoplasmic division of Xenopus embryo by rho p21 and its inhibitory GDP/GTP exchange protein (rho GDI). J. Cell Biol. 120: 1187-1195.

Lehner, C.F. 1992. The pebble gene is required for cytokinesis in Drosophila. J. Cell Sci. 103: 1021-1030.

Liu, X., H. Wang, M. Eberstadt, A. Schnuchel, E.T. Olejniczak, R.P. Meadows, J.M. Schkeryantz, D.A. Janowick, J.E. Harlan, E.A. Harris et al. 1998. NMR structure and mutagenesis of the N-terminal Dbl homology domain of the nucleotide exchange factor Trio. Cell 95: 269-277.

Luo, L., Y.J. Liao, L.Y. Jan, and Y.N. Jan. 1994. Distinct morphogenetic functions of similar small GTPases: Drosophila Dracl is involved in axonal outgrowth and myoblast fusion. Genes \& Dev. 8: 1787-1802.

Mabuchi, I., Y. Hamaguchi, H. Fujimoto, N. Morii, M. Mishima, and S. Narumiya. 1993. A rho-like protein is involved in the organisation of the contractile ring in dividing sand dollar eggs. Zygote 1: 325-331.

Miki, T., C.L. Smith, J.E. Long, A. Eva, and T.P. Fleming. 1993. Oncogene ect2 is related to regulators of small GTP-binding proteins. Nature 362: 462-465.

Neufeld, T.P. and G.M. Rubin. 1994. The Drosophila peanut gene is required for cytokinesis and encodes a protein similar to yeast putative bud neck filament proteins. Cell 77: 371379.

Nishimura, Y., K. Nakano, and I. Mabuchi. 1998. Localization of Rho GTPase in sea urchin eggs. FEBS Lett. 441: 121-126.

O'Connell, C.B., S.P. Wheatley, S. Ahmed, and Y. Wang. 1999. The small GTP-binding protein Rho regulates cortical activities in cultured cells during division. J. Cell Biol. 144: 305313.

Ron, D., M. Zannini, M. Lewis, R.B. Wickner, L.T. Hunt, G. Graziani, S.R. Tronick, S.A. Aaronson, and A. Eva. 1991. A region of proto- $d b l$ essential for its transforming activity shows sequence similarity to a yeast cell cycle gene, CDC24, and the human breakpoint cluster gene, bcr. New Biol. 3: 372-379.

Salzberg, A., S.N. Prokopenko, Y. He, P. Tsai, M. Pal, P. Maroy, D.M. Glover, P. Deak, and H.J. Bellen. 1997. P-element insertion alleles of essential genes on the third chromosome of Drosophila melanogaster: Mutations affecting embryonic PNS development. Genetics 147: 1723-1741.

Schultz, J., F. Milpetz, P. Bork, and C.P. Ponting. 1998. SMART, a simple modular architecture research tool: Identification of signaling domains. Proc. Natl. Acad. Sci. 95: 5857-5864.

Schweighoffer, F., H. Cai, M.C. Chevallier-Multon, I. Fath, G. Cooper, and B. Tocque. 1993. The Saccharomyces cerevisiae SDC25 C-domain gene product overcomes the dominant inhibitory activity of Ha-Ras Asn-17. Mol. Cell. Biol. 13: 3943.

Shaw, G. 1996. The pleckstrin homology domain: An intriguing multifunctional protein module. BioEssays 18: 35-46.

Soisson, S.M., A.S. Nimnual, M. Uy, D. Bar-Sagi, and J. Kuriyan. 1998. Crystal structure of the Dbl and pleckstrin homology domains from the human Son of sevenless protein. Cell 95: 259-268. 
Sone, M., M. Hoshino, E. Suzuki, S. Kuroda, K. Kaibuchi, H. Nakagoshi, K. Saigo, Y. Nabeshima, and C. Hama. 1997. Still life, a protein in synaptic terminals of Drosophila homologous to GDP-GTP exchangers. Science 275: 543-547.

Sterpetti, P., A.A. Hack, M.P. Bashar, B. Park, S. Cheng, J.H.M. Knoll, T. Urano, L.A. Feig, and D. Toksoz. 1999. Activation of the Lbc Rho exchange factor proto-oncogene by truncation of an extended $\mathrm{C}$ terminus that regulates transformation and targeting. Mol. Cell. Biol. 19: 1334-1345.

Steven, R., T.J. Kubiseski, H. Zheng, S. Kulkarni, J. Mancillas, A. Ruiz Morales, C.W. Hogue, T. Pawson, and J. Culotti. 1998. UNC-73 activates the Rac GTPase and is required for cell and growth cone migrations in C. elegans. Cell 92: 785795.

Strutt, D.I., U. Weber, and M. Mlodzik. 1997. The role of RhoA in tissue polarity and Frizzled signalling. Nature 387: 292295.

Takaishi, K., T. Sasaki, T. Kameyama, S. Tsukita, and Y. Takai. 1995. Translocation of activated Rho from the cytoplasm to membrane ruffling area, cell-cell adhesion sites and cleavage furrows. Oncogene 11: 39-48.

Van Aelst, L. and C. D'Souza-Schorey. 1997. Rho GTPases and signaling networks. Genes \& Dev. 11: 2295-2322.

Wasserman, S. 1998. FH proteins as cytoskeletal organizers. Trends Cell Biol. 8: 111-115.

Watanabe, N., P. Madaule, T. Reid, T. Ishizaki, G. Watanabe, A. Kakizuka, Y. Saito, K. Nakao, B.M. Jockusch, and S. Narumiya. 1997. p140mDia, a mammalian homolog of Drosophila diaphanous, is a target protein for Rho small GTPase and is a ligand for profilin. EMBO J. 16: 3044-3056.

Whitehead, I., H. Kirk, C. Tognon, G. Trigo-Gonzalez, and R. Kay. 1995. Expression cloning of $1 f c$, a novel oncogene with structural similarities to guanine nucleotide exchange factors and to the regulatory region of protein kinase C. J. Biol. Chem. 270: 18388-18395.

Whitehead, I.P., S. Campbell, K.L. Rossman, and C.J. Der. 1997. Dbl family proteins. Biochim. Biophys. Acta 1332: F1-F23.

Yamane, K., M. Kawabata, and T. Tsuruo. 1997. A DNA-topoisomerase-II-binding protein with eight repeating regions similar to DNA-repair enzymes and to a cell-cycle regulator. Eur. J. Biochem. 250: 794-799.

Yasui, Y., M. Amano, K. Nagata, N. Inagaki, H. Nakamura, H. Saya, K. Kaibuchi, and M. Inagaki. 1998. Roles of Rho-associated kinase in cytokinesis; mutations in Rho-associated kinase phosphorylation sites impair cytokinetic segregation of glial filaments. J. Cell Biol. 143: 1249-1258.

Zheng, Y., M.J. Hart, and R.A. Cerione. 1995. Guanine nucleotide exchange catalyzed by $d b l$ oncogene product. Methods Enzymol. 256: 77-84.

Zheng, Y., D. Zangrilli, R.A. Cerione, and A. Eva. 1996. The pleckstrin homology domain mediates transformation by oncogenic $d b l$ through specific intracellular targeting. $J$. Biol. Chem. 271: 19017-19020.

Zinn, K., L. McAllister, and C.S. Goodman. 1988. Sequence analysis and neuronal expression of fasciclin I in grasshopper and Drosophila. Cell 58: 577-587. 


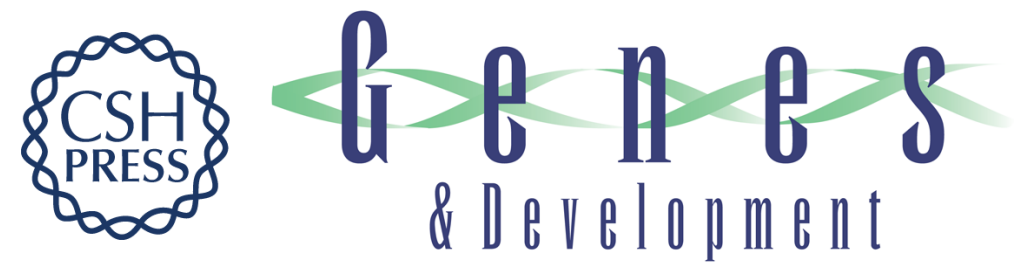

\section{A putative exchange factor for Rho1 GTPase is required for initiation of cytokinesis in Drosophila}

Sergei N. Prokopenko, Anthony Brumby, Louise O'Keefe, et al.

Genes Dev. 1999, 13:

References This article cites 66 articles, 39 of which can be accessed free at:

http://genesdev.cshlp.org/content/13/17/2301.full.html\#ref-list-1

License

Email Alerting

Receive free email alerts when new articles cite this article - sign up in the box at the top

Service right corner of the article or click here.

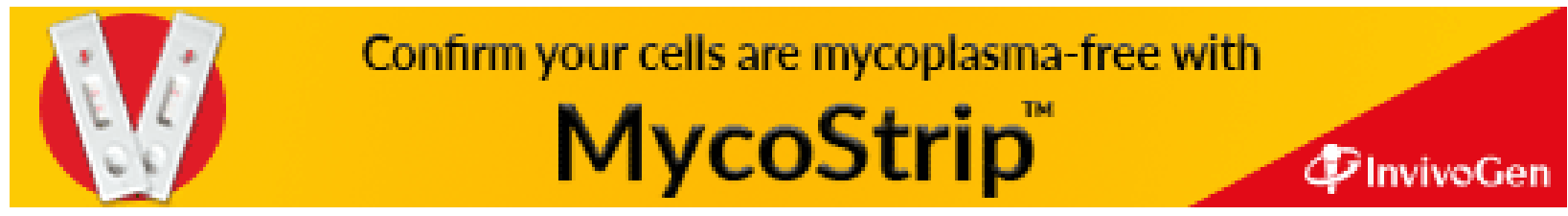

